OPEN ACCESS

Edited by:

Leilei Xu,

Nanjing University of Information Science and Technology, China

Reviewed by:

Miao Zhichao,

Shandong University of

Technology, China

Bo Yang,

Nanjing University of Information

Science and Technology, China

Mei Wu,

Huaiyin Institute of Technology, China

Qinghui Shou,

Qingdao Institute of Bioenergy and Bioprocess Technology (CAS), China

${ }^{*}$ Correspondence:

Nannan Wang

wangnn@dgut.edu.cn

Wenlong Wang

2016833@dgut.edu.cn

Lifeng Cui

lcui@dgut.edu.cn

tThese authors have contributed equally to this work

Specialty section

This article was submitted to Catalysis and Photocatalysis,

a section of the journal

Frontiers in Chemistry

Received: 15 May 2020

Accepted: 09 July 2020

Published: 31 August 2020

Citation:

Chen X, Chen Y, Song C, Ji P,

Wang N, Wang $W$ and Cui $L$ (2020) Recent Advances in Supported Metal Catalysts and Oxide Catalysts for the

Reverse Water-Gas Shift Reaction.

Front. Chem. 8:709.

doi: 10.3389/fchem.2020.00709

\section{Recent Advances in Supported Metal Catalysts and Oxide Catalysts for the Reverse Water-Gas Shift Reaction}

\author{
Xiaodong Chen ${ }^{1,2,3 \dagger}$, Ya Chen ${ }^{4 \dagger}$, Chunyu Song ${ }^{1,2 \dagger}$, Peiyi $\mathrm{Ji}^{5}$, Nannan Wang ${ }^{1 *}$, \\ Wenlong Wang ${ }^{1 *}$ and Lifeng Cui ${ }^{1 *}$
}

\begin{abstract}
'School of Materials Science and Engineering, Dongguan University of Technology, Dongguan, China, ${ }^{2}$ Center for Clean Energy Technology, Faculty of Science, School of Mathematical and Physical Science, University of Technology Sydney, Sydney, NSW, Australia, ${ }^{3}$ Department of Applied Chemistry, School of Science, Xi'an Jiaotong University, Xi'an, China, ${ }^{4}$ School of Physical Science and Technology, ShanghaiTech University, Shanghai, China, ${ }^{5}$ College of Chemistry and Materials Science, Shanghai Normal University, Shanghai, China
\end{abstract}

The reverse water-gas shift reaction (RWGSR), a crucial stage in the conversion of abundant $\mathrm{CO}_{2}$ into chemicals or hydrocarbon fuels, has attracted extensive attention as a renewable system to synthesize fuels by non-traditional routes. There have been persistent efforts to synthesize catalysts for industrial applications, with attention given to the catalytic activity, CO selectivity, and thermal stability. In this review, we describe the thermodynamics, kinetics, and atomic-level mechanisms of the RWGSR in relation to efficient RWGSR catalysts consisting of supported catalysts and oxide catalysts. In addition, we rationally classify, summarize, and analyze the effects of physicochemical properties, such as the morphologies, compositions, promoting abilities, and presence of strong metal-support interactions (SMSI), on the catalytic performance and CO selectivity in the RWGSR over supported catalysts. Regarding oxide catalysts (i.e., pure oxides, spinel, solid solution, and perovskite-type oxides), we emphasize the relationships among their surface structure, oxygen storage capacity (OSC), and catalytic performance in the RWGSR. Furthermore, the abilities of perovskite-type oxides to enhance the RWGSR with chemical looping cycles (RWGSR-CL) are systematically illustrated. These systematic introductions shed light on development of catalysts with high performance in RWGSR.

Keywords: RWGSR, catalytic mechanism, catalytic performance, supported metal catalysts, oxide catalysts, chemical looping cycles

\section{INTRODUCTION}

The increasing emissions of anthropogenic $\mathrm{CO}_{2}$ into our atmosphere through the unrestricted use of fossil fuels to drive industrial processes and human activity, particularly over the past few decades, has resulted in damage to the "carbon neutral" status of the earth and thus caused serious harm to the ecological system and to sustainable human development (Aresta et al., 2014). Therefore, the extensive efforts are needed to develop $\mathrm{CO}_{2}$ utilization technologies to address these issues (Mikkelsen et al., 2010). Benefiting from plentiful low-cost $\mathrm{CO}_{2}$ raw materials as well as the increasingly advanced $\mathrm{CO}_{2}$ capture and separation technologies, $\mathrm{CO}_{2}$ utilization is promising for commercial-scale applications (Aresta et al., 2016; Klankermayer et al., 2016). 
The reverse water-gas shift reaction (RWGSR) is an indispensable part of $\mathrm{CO}_{2}$ utilization because it is a nonfossil route for providing feedstock for important chemical processes, such as methanol synthesis (Gao et al., 2016; Huš et al., 2017), Fischer-Tropsch synthesis (Riedel et al., 1999), and Monsanto/Cativa acetic acid synthesis (Maitlis et al., 1996; Jones, 2000). When it is used as an intermediate step in the direct thermochemical transformation of $\mathrm{CO}_{2}$ to hydrocarbons, such as methane (Sahebdelfar and Takht Ravanchi, 2015; Avanesian et al., 2016), ethanol (Sahebdelfar and Takht Ravanchi, 2015), lowcarbon olefin (Liu et al., 2008; Zheng et al., 2017), and dimethyl ether (Centi and Perathoner, 2009), the RWGSR renders the process more practical. An important workable application of the RWGSR is associated with scarce $\mathrm{H}_{2}$ reutilization in the Mars Exploration Program, in which it could regenerate $\mathrm{H}_{2} \mathrm{O}$ more easily for astronauts to utilize (Avanesian et al., 2016). In biomass-based solid oxide fuel cells, the ratio of $\mathrm{CO}_{2} / \mathrm{CO} / \mathrm{H}_{2}$ in the biomass gas can be considerably dictated by the RWGSR to realize its maximum energy storage efficiency (Chen et al., 2017a). Additionally, the RWGSR can be used to couple $\mathrm{CO}_{2}$ with alkylene oxide or low alkanes to generate valuable chemicals, including ethylene glycol (Arunajatesan et al., 2001), styrene (Burri et al., 2007; Batista et al., 2010), and light olefins (Mukherjee et al., 2016; Kang et al., 2017). In contrast to the direct thermal cracking process, these coupled reactions can effortlessly break the thermodynamic equilibrium constraints and effectively accelerate their utilization (Reddy et al., 2008; Rao et al., 2009).

The chemically inert $\mathrm{CO}_{2}$, with its high $\mathrm{C}-\mathrm{O}$ bond energy of $806 \mathrm{~kJ} \mathrm{~mol}^{-1}$, enables the chemical transformation of $\mathrm{CO}_{2}$ to CO via the RWGSR (Wang et al., 2011). According to activation theory, the adsorption of $\mathrm{CO}_{2}$ on the oxygen vacancy sites of certain catalysts initiates the first step of the RWGSR when it involves the cleavage of its own C-O bond under thermal energy-driven conditions (Su et al., 2019). There are two idiographic activation mechanisms proposed for the production of CO from the RWGSR based on experimental observations and theoretical calculations (Goguet et al., 2016). The first pathway is $\mathrm{CO}_{2}$ hydrogenation to $\mathrm{CO}$ via the RWGSR, which proceeds via more reactive carboxyl $\left(\mathrm{COOH}^{*}\right)$ or formate $\left(\mathrm{HCOO}^{*}\right)$ intermediates, and the other pathway is the decomposition of $\mathrm{CO}_{2}$ to $\mathrm{CO}^{*}+\mathrm{O}^{*}$ via the direct $\mathrm{C}-\mathrm{O}$ bond cleavage pathway (Weatherbee and Bartholomew, 1984; Kattel et al., 2016a). Once activated, these adsorbed intermediates will be instantaneously dissociated or desorbed on the constructed active centers of these catalysts to form the CO product (Tang et al., 2009; Roiaz et al., 2016). Based on this objective analysis, it is imperative to develop effective catalysts for $\mathrm{CO}_{2}$ activation in the RWGSR.

In this review, we concentrate on the catalytic performance of the RWGSR with two major categories of heterogeneous catalysts, including supported metal catalysts and oxide catalysts, which is a subject of increasing interest. Utilizing the thermodynamics and kinetics analyses and the atomic-level mechanisms, the principles of RWGSR catalyst design will be comprehensively described. In addition, the physicochemical properties of supported catalysts, such as the morphologies, compositions, promoting abilities, and presence of metalsupport interactions, which affect the catalytic activity and CO selectivity of the RWGSR, will be systematically introduced to elucidate the structure-activity relationships. The relationships among the surface structure, oxygen storage capacity (OSC) and catalytic performance of oxide catalysts in the RWGSR are highlighted, especially for the application of perovskite-type oxides to enhance the RWGSRCL. The present review provides general guidelines for the state-of-the-art architecture of heterogeneous catalysts for the RWGSR and a discussion of their challenges and further prospects.

\section{THERMODYNAMIC ANALYSIS}

Since $\mathrm{CO}$ is arguably the most important C1-builiding block, the synthetic route of " $\mathrm{CO}_{2}$-to-CO" is considered an economical and valuable strategy (Barnard, 2008; Brennführer et al., 2009; Wu et al., 2011). Based on the thermodynamic standard enthalpy, the transformation of $\mathrm{CO}_{2}$ to $\mathrm{CO}$ via the RWGSR is more thermodynamically favorable at elevated temperature because it is reversible and endothermic and because its chemical equilibrium is pressure independent, as shown in Equation (1). However, the RWGSR is always accompanied by undesired $\mathrm{CO}_{2}$ methanation over the catalysts because of its excessive hydrogenation under ambient pressure (Kim et al., 2015; Ishito et al., 2016; Zhou et al., 2017). In addition, methanation is exothermic, favored at lower temperature, and pressure dependent, as shown in Equation (2).

$$
\begin{array}{r}
\mathrm{CO}_{2}+\mathrm{H}_{2} \rightarrow \mathrm{CO}+\mathrm{H}_{2} \mathrm{O} \Delta_{\mathrm{r}} H^{\theta}(298.15 \mathrm{~K}) \\
=+40.6 \mathrm{~kJ} \mathrm{~mol}^{-1} . \\
\mathrm{CO}_{2}+4 \mathrm{H}_{2} \rightarrow \mathrm{CH}_{4}+2 \mathrm{H}_{2} \mathrm{O} \Delta_{\mathrm{r}} H^{\theta}(298.15 \mathrm{~K}) \\
=-165.0 \mathrm{~kJ} \mathrm{~mol}^{-1} .
\end{array}
$$

For both the parallel and the cascade reactions over the catalysts, the $\mathrm{CO}$ yield is seriously restricted to $\mathrm{H}_{2}$ utilization in additional competitive methanations. From the thermodynamic standpoint, as shown in Figure 1, the equilibrium composition favors the production of $\mathrm{CH}_{4}$ rather than that of $\mathrm{CO}$ in the RWGSR at lower temperatures. Therefore, it is challenging to construct heterogeneous catalysts to restrict the production of undesirable $\mathrm{CH}_{4}$ as a lower value-added by-product for applications at lower temperatures.

\section{MECHANISM}

The well-known catalytic mechanisms proposed for the RWGSR reaction can be classified into two categories: surface redox mechanisms and associative mechanisms (Su et al., 2017). The major difference between these mechanisms is whether the dissociated $\mathrm{H}_{2}$ species is involved in the formation of the carboncontaining intermediates, namely, formats, and carboxyls (Lin et al., 2017). 


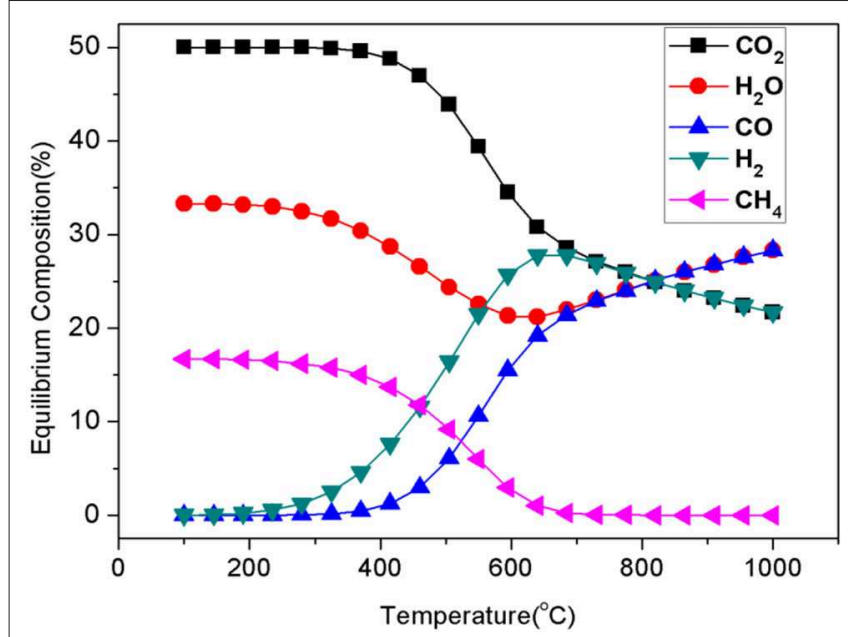

FIGURE 1 | Equilibrium composition of the RWGSR and $\mathrm{CO}_{2}$ methanation $\left(\mathrm{CO}_{2}: \mathrm{H}_{2}=1: 1\right)$.

\section{Surface Redox Mechanism}

The alternative oxido-reduction of active sites on the catalyst surface in the atmosphere of $\mathrm{CO}_{2} / \mathrm{H}_{2}$ feedstock is believed to be a prerequisite for the sustainability of the RWGSR. For Cu-based catalysts, e.g., the reaction mechanism can be described as follows (Chen et al., 2000; Xu and Ge, 2016):

$$
\begin{aligned}
& \mathrm{CO}_{2}(\mathrm{~g})+2 \mathrm{Cu}^{0}(\mathrm{~s}) \rightarrow \mathrm{CO}(\mathrm{g})+\mathrm{Cu}_{2} \mathrm{O}(\mathrm{s}) \\
& \mathrm{H}_{2}(\mathrm{~g})+\mathrm{Cu}_{2} \mathrm{O}(\mathrm{s}) \rightarrow \mathrm{H}_{2} \mathrm{O}(\mathrm{s})+2 \mathrm{Cu}^{0}(\mathrm{~s}) .
\end{aligned}
$$

In these reactions, $\mathrm{Cu}^{0}$, the active site in the RWGSR, is involved in the rate-controlling step, $\mathrm{CO}_{2}$ reduction. The $\mathrm{CO}_{2}$ oxidizes the $\mathrm{Cu}^{0}$ to generate $\mathrm{Cu}^{+}$and $\mathrm{CO}$, while the $\mathrm{H}_{2}$ reduces the $\mathrm{Cu}^{+}$ to $\mathrm{Cu}^{0}$ to form $\mathrm{H}_{2} \mathrm{O}$; thus, the reaction conforms to a redox mechanism. When the whole catalytic process of the RWGSR is considered in detail, the mechanism of the surface redox reaction can be decomposed into the following basic steps (“*” denotes the vacancy sites) (Gines et al., 1997; Fornero et al., 2017):

$$
\begin{array}{r}
\mathrm{CO}_{2}(\mathrm{~g})+2^{*} \rightarrow \mathrm{CO}^{*}+\mathrm{O}^{*} \\
\mathrm{CO}^{*} \rightarrow \mathrm{CO}(\mathrm{g})+^{*} \\
\mathrm{H}_{2}(\mathrm{~g})+2^{*} \rightarrow 2 \mathrm{H}^{*} \\
2 \mathrm{H}^{*}+\mathrm{O}^{*} \rightarrow \mathrm{H}_{2} \mathrm{O}^{*}+2^{*} \\
\mathrm{H}_{2} \mathrm{O}^{*} \rightarrow \mathrm{H}_{2} \mathrm{O}(\mathrm{g})+^{*}
\end{array}
$$

The study of kinetics is an important tool for establishing the redox mechanism of the RWGSR. Based on the Monte Carlo method to approximately simulate the RWGSR process over the $\mathrm{Cu}$-based catalysts, $\mathrm{CO}_{2}$ dissociates immediately to give $\mathrm{CO}$ and adsorbed oxygen species and is then reduced by $\mathrm{H}_{2}$ with equivalent stoichiometric coefficients (Gines et al., 1997; Xu and $\mathrm{Ge}, 2016)$. In this process, the dissociative adsorption of $\mathrm{CO}_{2}$ on the $\mathrm{Cu}$ particles is the rate-determining step, and the reduction of the adsorbed oxygen-containing species and surface hydroxyls follows (Fujita et al., 1992; Wang et al., 2013b). Realtime temporal analysis of the products confirms that a surfacereduced $\mathrm{Au} / \mathrm{CeO}_{2}$ catalyst can be reoxidized by exposure to $\mathrm{CO}_{2}$ pulses and that the surface oxygen deposited in this way can be reactively removed again, which is a prerequisite for the redox mechanism in the RWGSR. Furthermore, neglecting the changes in the hydroxyls and $\mathrm{H}_{2} \mathrm{O}$ on the surface imposed by the presence of $\mathrm{H}_{2}$ in the feed, the activity for active oxygen deposition is sufficient to make the redox mechanism the dominant reaction pathway (Fornero et al., 2017). Realistically, the RWGSR proceeds though a redox mechanism over $\mathrm{Au} / \mathrm{TiO}_{2}$ catalysts in which the existing surface hydroxyls, surface $\mathrm{Ti}^{3+}$, and oxygen vacancies can jointly participate in the formation of a hydroxycarbonyl intermediate, which quickly decomposes to CO (Bobadilla et al., 2018). According to Density Functional Theory (DFT) calculations, the RWGSR on $\mathrm{Cu@Mo} 2 \mathrm{C}(001)$ is preferentially selective for CO via a redox mechanism, and compared to the reaction via a $\mathrm{COOH}$ mechanism, the $\mathrm{HCOO}$ mechanism is kinetically less favorable due to its higher activation barrier in the rate-determining step, as shown in Figure 2. In the same way as the redox mechanism, the RWGSR occurs first by spontaneous dissociation of $\mathrm{H}_{2}$ to form $\mathrm{H}^{*}$, second by $\mathrm{CO}^{*}$ and $\mathrm{O}^{*}$ formation from the direct $\mathrm{C}-\mathrm{O}$ bond cleavage of molecular $\mathrm{CO}_{2}$, third by the reaction of $\mathrm{H}^{*}$ and $\mathrm{O}^{*}$ to produce $\mathrm{OH}^{*}$, fourth by the reaction of two $\mathrm{OH}^{*}$ species to generate $\mathrm{H}_{2} \mathrm{O}^{*}$, and finally by the desorption of $\mathrm{CO}$ and $\mathrm{H}_{2} \mathrm{O}$ gas on the $\mathrm{Cu} @ \mathrm{Mo}_{2} \mathrm{C}$ (001) catalyst. Notably, the step for $\mathrm{OH}^{*}$ formation rather than $\mathrm{CO}^{*}$ formation in the redox mechanism, which has a higher activation barrier of $1.4 \mathrm{eV}$, is the rate-determining step (Jing et al., 2019).

\section{Associative Mechanism Formate Species}

The RWGSR pathway involves a formate $\left(\mathrm{HCOO}^{*}\right)$ intermediate that is formed by the initial $\mathrm{CO}_{2}{ }^{*}$ hydrogenation step and subsequently undergoes an instantaneous dissociation reaction to produce CO (Arunajatesan et al., 2007; Cao et al., 2016; Chen et al., 2016; Wolf et al., 2016). The reaction is described by the following steps (“*” denotes the vacancy sites) (Chen et al., 2017a,b):

$$
\begin{array}{r}
\mathrm{H}_{2}(\mathrm{~g})+2^{*} \rightarrow \mathrm{H}^{*}+\mathrm{H}^{*} \\
\mathrm{CO}_{2}(\mathrm{~g})+^{*} \rightarrow \mathrm{CO}_{2}{ }^{*} \\
\mathrm{CO}_{2}{ }^{*}+\mathrm{H}^{*} \rightarrow \mathrm{HCOO}^{*}+^{*} \\
\mathrm{HCOO}^{*}\left(\mathrm{COOH}^{*}\right)+^{*} \rightarrow \mathrm{HCO}^{*}\left(\mathrm{COH}^{*}\right)+\mathrm{O}^{*} \\
\mathrm{HCO}^{*}\left(\mathrm{COH}^{*}\right)+^{*} \rightarrow \mathrm{CO}^{*}+\mathrm{H}^{*} \\
\mathrm{H}^{*}+\mathrm{O}^{*} \rightarrow \mathrm{OH}^{*}+^{*} \\
\mathrm{H}^{*}+\mathrm{OH}^{*} \rightarrow \mathrm{H}_{2} \mathrm{O}^{*} \\
\mathrm{H}_{2} \mathrm{O}^{*} \rightarrow \mathrm{H}_{2} \mathrm{O}(\mathrm{g})+^{*} \\
\mathrm{CO}^{*} \rightarrow \mathrm{CO}(\mathrm{g})+{ }^{*}
\end{array}
$$

As indicated by the temperature-programmed desorption spectra of $\mathrm{H}_{2} / \mathrm{CO}_{2}$ co-adsorbed on $\mathrm{Cu} / \mathrm{SiO}_{2}$ and $\mathrm{Cu} / \mathrm{K} / \mathrm{SiO}_{2}$ catalysts, the $\mathrm{H}$ atoms either associate with $\mathrm{CO}_{2}-\mathrm{Cu}$ to form formates or 


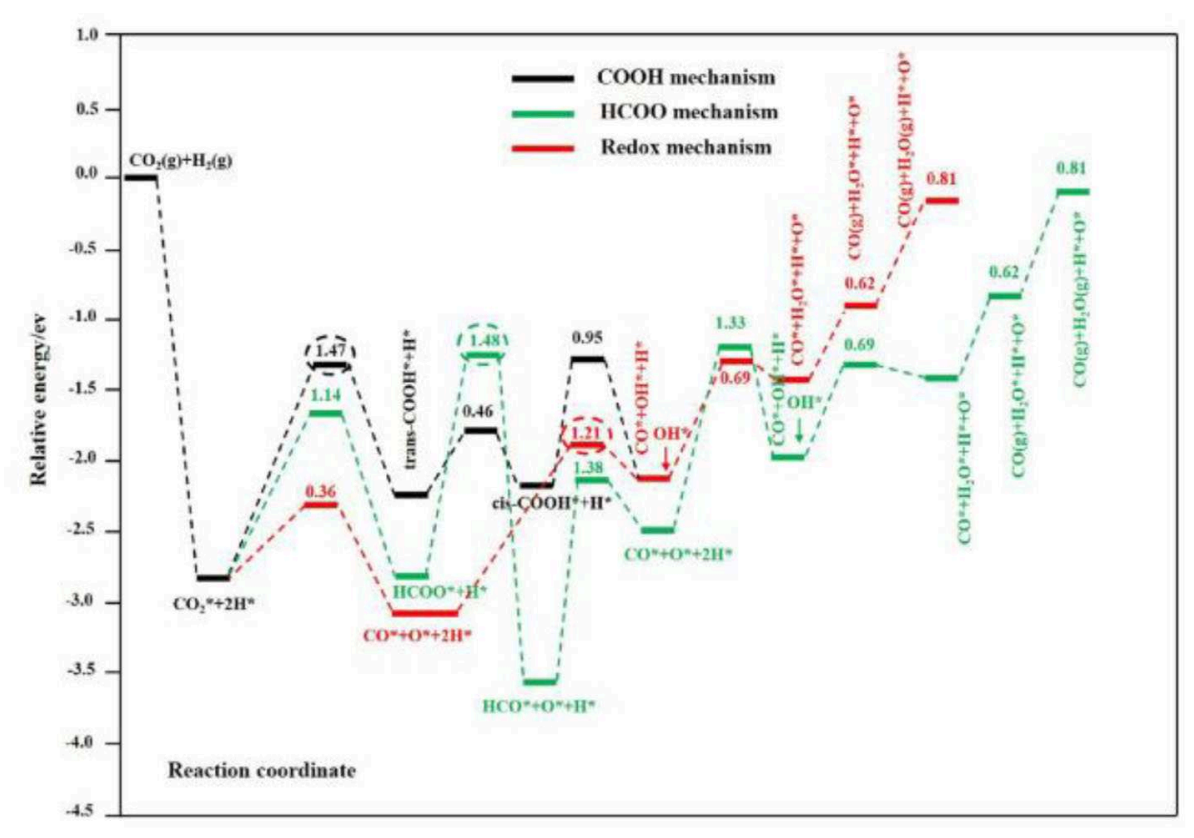

FIGURE 2 | Calculated potential energy profile of the most favorable redox (red line), HCOO (green line), and COOH (black line) mechanisms for the RWGSR on the Cu@Mo2C (001) surface. The numbers in the figure are the activation barriers of the elementary steps. The numbers in red, green, and black circles are the activation barriers of the rate-limiting steps in the redox, $\mathrm{HCOO}$, and $\mathrm{COOH}$ pathways, respectively. Reprinted with permission from Jing et al. (2019). Copyright (2019) American Chemical Society.

migrate to the surfaces of the interfacial sites, resulting in the formation of $\mathrm{K}_{2} \mathrm{O}$ and $\mathrm{CO}$ by decomposition (Chen and Cheng, 2002; Chen et al., 2003). Regarding the chemical state of $\mathrm{Cu}$ in the RWGSR, the $\mathrm{Cu}^{0}$ and $\mathrm{Cu}^{+}$atoms are proposed to coexist on the $\mathrm{Cu}$-based catalyst surface, and their roles are possibly to dissociate $\mathrm{H}_{2}$ and stabilize the formats, respectively (Chen et al., 2000). Based on transient diffused reflection Fourier transform infrared spectroscopy (DRIFTS), the appearance of interfacial sites may result from an electron transfer from the $\mathrm{Pt}$ to the neighboring $\mathrm{O}$ in the $\mathrm{KO}_{\mathrm{x}}$ species over the $\mathrm{Pt} / \mathrm{K} /$ mutille and $\mathrm{Pt} / \mathrm{K} / \mathrm{L}$ catalysts, which are responsible for the decomposition of the formates to produce CO (Liang et al., 2017; Yang et al., 2017). The in-situ DRIFTS also shows that when strong basic sites, such as those of $\mathrm{KOH}$, are introduced into $\mathrm{Ni} / \mathrm{Al}_{2} \mathrm{O}_{3}$ catalysts, the formates instead of the carbonates are strongly absorbed on their surface, promoting the hydrogenation of $\mathrm{CO}_{2}$ to $\mathrm{CO}$ via the RWGSR (Zhang et al., 2019a). For $\mathrm{Cu} / \mathrm{CeO}_{2}$-nanorode catalysts, in-situ DRIFTS points to bidentate formate as the active intermediates for the RWGSR because the preferential formation of a high bidentate formate coverage on their surface may have the surface geometry of a $\mathrm{CeO}_{2}$ (110) termination in which the nearest surface oxygen distance is $2.71 \AA$, which is a more suitable spacing for the formation of bidentate formates and could thus be the main reason for the excellent performance (Lin et al., 2018a,b). The results from in-situ DRIFTS indicate that the $\mathrm{CO}_{2}$ must first react with the surface hydroxyls on $\mathrm{Al}_{2} \mathrm{O}_{3}$ to form bicarbonates, which subsequently react with the adsorbed $\mathrm{H}$ on $\mathrm{Ru}$ or $\mathrm{Au}$ to produce adsorbed formates, most likely at the metal/oxide interface, and then react rapidly with the adsorbed $\mathrm{H}$ to form CO (Wang et al., 2016a; Bobadilla et al., 2018). Based on a steady-state isotopic transient kinetic analysis, the disappearance trend of the infrared signatures of $\mathrm{H}^{12} \mathrm{COO}^{*}$ is consistent with the MS signals of ${ }^{12} \mathrm{CO}$ products when the feed gas is switched from ${ }^{12} \mathrm{CO}_{2} / \mathrm{H}_{2} / \mathrm{Ar}$ to ${ }^{13} \mathrm{CO}_{2} / \mathrm{H}_{2} / \mathrm{Ar}$ over a $\mathrm{Pd} / \mathrm{Al}_{2} \mathrm{O}_{3}$ catalyst, suggesting that $\mathrm{H}^{12} \mathrm{COO}^{*}$ is the reactive intermediate rather than a spectator, and the rate-determining step for the CO formation is related to HCOO* (Wang et al., 2017). DFT calculations demonstrate that a formate mechanism is feasible for the RWGSR catalyzed by $\mathrm{M}_{1} / \mathrm{W}_{6} \mathrm{~S}_{8}(\mathrm{M}=\mathrm{Fe}, \mathrm{Ru}$, and Os). More concretely, $\mathrm{HCOO}^{*}$ formation starts with the most stable adsorption configuration of $\mathrm{CO}_{2}{ }^{*}$, in which an $\mathrm{H}^{*}$ is placed on the $\mathrm{S}$ site, and $\mathrm{H}^{*}$ tends to attack the $\mathrm{C}$ atom of $\mathrm{CO}_{2}$ to form a C-H bond. When $\mathrm{HCOO}^{*}$ is formed, it is hydrogenated to form a $\mathrm{HCOOH}^{*}$ intermediate with a relatively low activation energy barrier, and the conversion will proceed to form the final product, $\mathrm{CO}$. In the overall process, the $\mathrm{H}_{2}$ dissociation on $\mathrm{M}_{1} / \mathrm{W}_{6} \mathrm{~S}_{8}(\mathrm{M}=\mathrm{Fe}, \mathrm{Ru}$, and $\mathrm{Os})$ is the rate-determining step (Zhang et al., 2018).

\section{Carboxyl Species}

The carbonyl species, the predominately active intermediate, is selectivity produced through activation of the $\mathrm{C}-\mathrm{O}$ bond of the $\mathrm{CO}_{2}$ molecule followed by $\mathrm{H}$-assisted formation of $\mathrm{COOH}^{*}$ (Tibiletti et al., 2004; Kim et al., 2012a,b). This intermediate immediately decomposes into CO by two different 


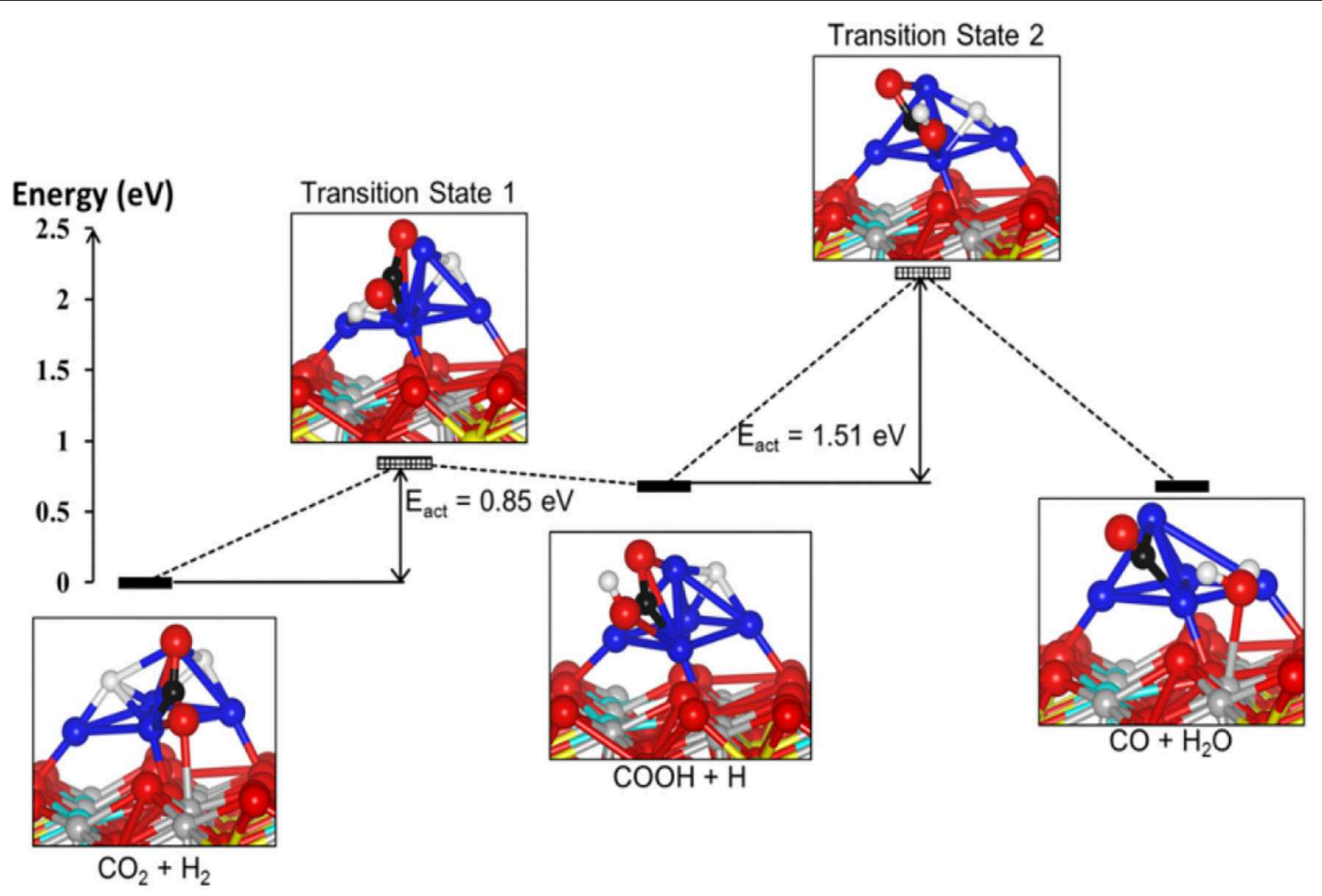

FIGURE 3 | Energy profile showing the reactants, intermediates, transition states, and final products for the RWGSR on the Nis $/$ YSZ(111) interface (Color key: O, Zr, $\mathrm{Y}, \mathrm{Ni}, \mathrm{C}$, and $\mathrm{H}$ are represented by red, gray, cyan, blue, black, and white spheres, respectively. The yellow spheres represent the oxygen vacancies). Reprinted with permission from Cadi-Essadek et al. (2018). Copyright (2018) American Chemical Society.

pathways, as shown below (“*” denotes the vacancy sites) (Chen et al., 2017a,b).

\begin{tabular}{lll}
\hline (I) $\mathrm{H}_{2}(\mathrm{~g})+2^{*} \rightarrow \mathrm{H}^{*}+\mathrm{H}^{*}$ & (1) & (II) $\mathrm{H}(\mathrm{g})+2^{*} \rightarrow \mathrm{H}^{*}+\mathrm{H}^{*}$ \\
$\mathrm{CO}_{2}(\mathrm{~g})+^{*} \rightarrow \mathrm{CO}_{2}{ }^{*}$ & (2) & $\mathrm{CO}_{2}(\mathrm{~g})+^{*} \rightarrow \mathrm{CO}_{2}$ \\
$\mathrm{CO}_{2}{ }^{*}+\mathrm{H}^{*} \rightarrow\left(\mathrm{COOH}^{*}\right)+^{*}$ & (3) & $\mathrm{CO}_{2}{ }^{*}+\mathrm{H}^{*} \rightarrow\left(\mathrm{COOH}^{*}\right)+^{*}$ \\
$\mathrm{COOH}^{*}+^{*} \rightarrow \mathrm{CO}^{*}+\mathrm{OH}^{*}$ & (4) & $\mathrm{COOH}^{*}+^{*} \rightarrow \mathrm{HCO}^{*}\left(\mathrm{COH}^{*}\right)+\mathrm{O}^{*}$ \\
$\mathrm{H}^{*}+\mathrm{OH}^{*} \rightarrow \mathrm{H}_{2} \mathrm{O}^{*}$ & $(5)$ & $\mathrm{HCO}^{*}\left(\mathrm{COH}^{*}\right)+^{*} \rightarrow \mathrm{CO}^{*}+\mathrm{H}^{*}$ \\
$\mathrm{H}_{2} \mathrm{O}^{*} \rightarrow \mathrm{H}_{2} \mathrm{O}(\mathrm{g})+^{*}$ & $(6)$ & $\mathrm{H}^{*}+\mathrm{O}^{*} \rightarrow \mathrm{OH}^{*}+^{*}$ \\
$\mathrm{CO}^{*} \rightarrow \mathrm{CO}(\mathrm{g})+^{*}$ & $(7)$ & $\mathrm{H}^{*}+\mathrm{OH}^{*} \rightarrow \mathrm{H}_{2} \mathrm{O}^{*}$ \\
& & $\mathrm{H}_{2} \mathrm{O}^{*} \rightarrow \mathrm{H}_{2} \mathrm{O}(\mathrm{g})+^{*}$ \\
& & $\mathrm{CO} \rightarrow \mathrm{CO}(\mathrm{g})+^{*}$
\end{tabular}

On the basis of in-situ Fourier transform infrared spectroscopy (FT-IR) analyses, a $\mathrm{Pt} / \mathrm{TiO}_{2}$ catalyst treated at a high temperature and possessing reducible $\mathrm{TiO}_{2}$ sites but no $\mathrm{Pt}$ sites is exclusively active for $\mathrm{CO}$ product, and thus the carboxyl species formed on the reducible $\mathrm{TiO}_{2}$ sites are the intermediates in the formation of $\mathrm{CO}$ in the RWGSR (Kim et al., 2013). H/D isotopic substitution and kinetics and the results of the in-situ DRIFTS experiments illustrate that the $\mathrm{CO}$ formation proceeds via a mechanism in which $\mathrm{H}$ assists the dissociation of the $\mathrm{C}-\mathrm{O}$ bond and that a carboxyl is a more plausible intermediate than is a formate. In addition, the formates is still present on the $\mathrm{Cu}$ surface under the reaction conditions, but a fraction of them can be considered spectators of the reaction mechanism (Karelovic et al., 2019). The results from transient DRIFT-MS steady-state isotopic transient kinetic analysis analyses indicate that the characteristic exchange time (defined here as the time at which the DRIFTS signal of the intermediate decreases by $50 \%$ following the isotopic switch) of the carboxyl species agrees with that of the CO product (defined here as the time needed to achieve 50\% exchange between the two isotopes, e.g., ${ }^{12} \mathrm{CO}(\mathrm{g})$ and ${ }^{13} \mathrm{CO}(\mathrm{g})$ of the main reaction product from MS measurements) when the feed gas is switched from ${ }^{13} \mathrm{CO}_{2} / \mathrm{H}_{2}$ to ${ }^{12} \mathrm{CO}_{2} / \mathrm{H}_{2}$ over the $\mathrm{Pt} / \mathrm{CeO}_{2}$ catalyst. These data quantitatively demonstrated that, for the present catalyst and conditions, the main reaction pathway is the formation of $\mathrm{CO}$ from the carboxyl species at the oxygen vacancies over the Pt-CeO ${ }_{x}$ interface (Goguet et al., 2004a). DFT calculations indicate that the formation of $\mathrm{COOH}^{*}$ over $\mathrm{Mo}_{6} \mathrm{~S}_{8}-\mathrm{TM}(\mathrm{TM}=$ $\mathrm{Pd}, \mathrm{Pt}, \mathrm{Ag}$ ) nanoclusters by the binding of the $\mathrm{H}^{*}$ atom to the $\mathrm{O}$ atom of $\mathrm{CO}_{2}$ followed by its decomposition to $\mathrm{CO}$ is very favorable. Note that the $\mathrm{COOH}^{*}$ dissociation over $\mathrm{Mo}_{6} \mathrm{~S}_{8}-\mathrm{Ag}$ is the rate-determining step in the overall process, whereas the rate-determining step of $\mathrm{Mo}_{6} \mathrm{~S}_{8}-\mathrm{Pd}$ and $\mathrm{Mo}_{6} \mathrm{~S}_{8}-\mathrm{Pt}$ in the carboxyl pathway is the transition step of the $\mathrm{H}_{2}$ dissociation (Zheng et al., 2017). Moreover, DFT calculations show that the 
RWGSR complies with a carboxyl mechanism over a $\mathrm{Ni}_{5} / \mathrm{YSZ}$ (111) catalyst through the identification of the structures and calculation of the energies of the intermediate state and two transition states, as shown in Figure 3. It has been suggested that one of the $\mathrm{H}^{*}$ atoms migrates toward the nearest $\mathrm{O}$ atom of the $\mathrm{CO}_{2}{ }^{*}$ to form the $\mathrm{COOH}^{*}$ intermediate and subsequently involves its protonation, allowing the formation of $\mathrm{H}_{2} \mathrm{O}^{*}$ adsorbed on the surface and the $\mathrm{CO}^{*}$ adsorbed on the $\mathrm{Ni}$ cluster. This calculation also shows that the second transition state for the dissociation of the $\mathrm{COOH}^{*}$ intermediate is the rate-determining step of the overall pathway and has an energy barrier of $1.51 \mathrm{eV}$ (Cadi-Essadek et al., 2018).

\section{CATALYTIC SYSTEM}

In recent decades, heterogeneous catalysts that promote the RWGSR have been extensively studied because of the gradual realization of their widespread application prospects for $\mathrm{CO}_{2}$ utilization. At the early stage, much research has focused on the oxide catalysts due to their effluent oxygen vacancies sites, such as $\mathrm{CeO}_{2}, \mathrm{CuO}, \mathrm{ZnO}, \mathrm{Al}_{2} \mathrm{O}_{3}, \mathrm{Fe}_{2} \mathrm{O}_{3}, \mathrm{Cr}_{2} \mathrm{O}_{3}, \mathrm{In}_{2} \mathrm{O}_{3}$, and $\mathrm{MnO}_{2}$ (Saeidi et al., 2017; Su et al., 2017; He et al., 2019). Although the $\mathrm{CO}$ selectivities of these oxide catalysts are desirable in RWGSR, their disadvantages of lower $\mathrm{CO}_{2}$ activation and feasible poisons and sintering are hindering their extended application. In order to address these issues, persistent studies have concentrated on the fabrication of composite oxides (i.e., $\mathrm{CuO} / \mathrm{ZnO} / \mathrm{Al}_{2} \mathrm{O}_{3}, \mathrm{NiO} / \mathrm{CeO}_{2}, \mathrm{ZnO} / \mathrm{Al}_{2} \mathrm{O}_{3}, \mathrm{ZnO} / \mathrm{Cr}_{2} \mathrm{O}_{3}$, $\mathrm{CuOx} / \mathrm{CeO}_{2}, \mathrm{CuO}-\mathrm{CeO}_{2} / \mathrm{SBA}-15, \mathrm{In}_{2} \mathrm{O}_{3}-\mathrm{CeO}_{2}, \mathrm{FeO}$, etc.) (Liu et al., 2015; Dai et al., 2018; Ronda-Lloret et al., 2018; Panarities et al., 2020), spinel oxides (i.e., $\mathrm{ZnAl}_{2} \mathrm{O}_{4}, \mathrm{ZnCr}_{2} \mathrm{O}_{4}, \mathrm{CuAl}_{2} \mathrm{O}_{4}$, $\mathrm{CoAl}_{2} \mathrm{O}_{4}$, etc.) (Joo and Jung, 2003; Bahmanpour et al., 2019, 2020), solid solution oxides (i.e., $\mathrm{Zn}_{\mathrm{x}} \mathrm{Zr}_{1-\mathrm{x}} \mathrm{O}_{2-\mathrm{y}}, \mathrm{Ce}_{0.5} \mathrm{Zr}_{0.5} \mathrm{O}_{2}$, $\mathrm{Ni}_{\mathrm{x}} \mathrm{Ce}_{0.75} \mathrm{Zr}_{0.25-\mathrm{x}} \mathrm{O}_{2}$, etc.) (Zonetti et al., 2014), and perovskitetype oxides (i.e., $\mathrm{BaZr}_{0.8} \mathrm{Y}_{0.16} \mathrm{Zn}_{0.04} \mathrm{O}_{3}, \mathrm{La}_{0.75} \mathrm{Sr}_{0.25} \mathrm{CoO}_{3-\delta}$, $\mathrm{La}_{0.75} \mathrm{Sr}_{0.25} \mathrm{FeO}_{3}, \quad \mathrm{La}_{0.75} \mathrm{Sr}_{0.25} \mathrm{Fe}_{1-\mathrm{Y}} \mathrm{Cu}_{\mathrm{Y}} \mathrm{O}_{3}, \quad \mathrm{LaNiO}_{3}$, $\mathrm{La}_{0.9} \mathrm{Sr}_{0.1} \mathrm{NiO}_{3+\delta}, \quad \mathrm{La}_{0.9} \mathrm{Sr}_{0.1} \mathrm{FeO}_{3-\delta}, \quad \mathrm{La}_{0.9} \mathrm{Sr}_{0.1} \mathrm{Ni}_{0.5} \mathrm{Fe}_{0.5} \mathrm{O}_{3-\delta}$, $\mathrm{La}_{0.75} \mathrm{Sr}_{0.25} \mathrm{Cr}_{0.5} \mathrm{Mn}_{0.5} \mathrm{O}_{3-\delta}, \quad \mathrm{SrCe}_{0.9} \mathrm{Y}_{0.1} \mathrm{O}_{3-\delta}$, etc.) (Yamazoe et al., 1982; Ten Elshof et al., 1996; Klvana et al., 1999; Yang and Lin, 2006; Radovic et al., 2008; Zhuang et al., 2019; Bogolowski et al., 2020; Liu et al., 2020), which have the approvable characteristics of both stable structure and reverse oxygen storage capacity to increase RWGSR performance.

Recently, considerable efforts have been devoted to the design of metal-based catalysts (i.e., Pt, $\mathrm{Pd}, \mathrm{Au}, \mathrm{Rh}, \mathrm{Ru}, \mathrm{Cu}, \mathrm{Ni}, \mathrm{Re}, \mathrm{Co}$, $\mathrm{Fe}, \mathrm{Mo}$, etc.) immobilized onto the metal oxide support material (i.e., $\mathrm{CeO}_{2}, \mathrm{TiO}_{2}, \mathrm{Al}_{2} \mathrm{O}_{3}, \mathrm{ZnO}, \mathrm{ZrO}_{2}, \mathrm{SiO}_{2}$, etc.) (Goguet et al., 2004b; Wang et al., 2011; Liu et al., 2015; Álvarez Galván et al., 2016; Ro et al., 2016; Nielsen et al., 2018) because they have metal/oxide interfaces with high reducibility to facilitate $\mathrm{CO}_{2}$ activation in RWGSR. However, the $\mathrm{CH}_{4}$ may be easily produced on these catalysts in the case of excessive hydrogenation of the $\mathrm{C}-\mathrm{O}$ bond of the $\mathrm{CO}_{2}$ molecule, which can be detrimental to CO selectivity (Yeung et al., 2005; Sun et al., 2015; Wang et al., 2016b; Kattel et al., 2017). In reality, an effective supported metal catalyst must be capable of both the $\mathrm{C}-\mathrm{O}$ bond scission of $\mathrm{CO}_{2}$ and the appropriate hydrogenation. Thus, the supported metal catalysts must not only dissociate hydrogen relatively easily but also allow it to migrate onto the adjacent oxygen vacancies, where the adsorbed $\mathrm{CO}_{2}$ is further hydrogenated (Chen and Cheng, 2002; Wang et al., 2017). Furthermore, the details of the activity and selectivity of some representative RWGSR catalysts under reaction conditions are presented in Table 1.

\section{Supported Metal Catalysts}

The supported catalysts that can be seriously considered in the RWGSR due to their bifunctional catalytic roles for $\mathrm{CO}_{2}$ activation and appropriate hydrogenation (Porosoff et al., 2016). However, RWGSR is demonstrated to be structure sensitive reaction; thus, the CO selectivity of which can be dictated by tailoring the structure functionality of supported catalysts through the SMSI effect, metal size effect, shape and crystal face effect, bimetallic effect, and alkali promoter effect to boost their concentrated activity.

\section{Strong Metal-Support Interaction (SMSI) Effect}

The importance of support has been increasingly recognized in the decades following the discovery of SMSIs (Garin, 2001; Diebold, 2003; Neophytides et al., 2005; Fu and Wagner, 2007; Liu et al., 2013). In addition to dispersing metallic particles, the support also functions to influence the catalytic properties of the supported metal catalysts through geometric or electronic effects (Naito et al., 2006; Krstajić et al., 2008; Delgado et al., 2011; Li et al., 2015). In this section, the mechanisms by which SMSI effects provide catalytic characteristics of supported catalysts for the RWGSR are further elucidated.

The high electron donating property of metallic Pt in contact with a $\mathrm{Ti}^{3+}$ ion site is caused by the SMSI effect, which generates new $\mathrm{Pt}-\mathrm{O}_{\mathrm{v}}-\mathrm{Ti}^{3+}$ sites for $\mathrm{CO}$ production over the $\mathrm{Pt} / \mathrm{TiO}_{2}$ catalyst (Kim et al., 2012a,b, 2013). Additionally, by replacing the $\mathrm{ZrO}_{2}$ support by $\mathrm{TiO}_{2}$, the SMSI effect selectively weakens the binding of the $\mathrm{C}-\mathrm{O}$ bond and $\mathrm{O}$-bond intermediates at the PtCo-oxide interface, thus leading to the high selectivity toward CO in the RWGSR (Kattel et al., 2016b). For $\mathrm{TiO}_{2}$ supported Rh catalysts, an adsorbate-mediated SMSI (A-SMSI) encapsulation state can be formed as a result of its treatment in a $20 \mathrm{CO}_{2}: 2 \mathrm{H}_{2}$ environment at $250^{\circ} \mathrm{C}$. The high coverage of the adsorbates $\left(\mathrm{HCO}_{\mathrm{x}}\right)$ on the support induces oxygen vacancy formation, driving the migration of the $\mathrm{HCO}_{\mathrm{x}}$-functionalized support onto the metal. This A-SMSI encapsulation state is more stable against reoxidation by $\mathrm{H}_{2} \mathrm{O}$ in the RWGSR process compared with the SMSI encapsulation state formed as a result of only $\mathrm{H}_{2}$ treatment, which modifies the reactivity of all the remaining exposed $\mathrm{Rh}$ sites and appears to be comprehensive in covering the Rh but permeable to reactants, due to its amorphous properties. Consequently, formation of the A-SMSI state induces a selectivity switch in the $\mathrm{CO}_{2}$-reduction reaction from the $\mathrm{CH}_{4}$ production on the bare $\mathrm{Rh}$ particles to the $\mathrm{CO}$ product in the A-SMSI state, thus effectively rendering $\mathrm{Rh}$ less active for $\mathrm{C}-\mathrm{H}$ bond formation (Matsubu et al., 2017). For $\mathrm{Ir} / \mathrm{CeO}_{2}$ catalysts, the SMSIs can enable more oxygen atoms to be incorporated 
TABLE 1 | Summary of the reaction conditions with conversion to and selectivity for CO, when available, for selected RWGSR catalysts.

\begin{tabular}{|c|c|c|c|c|c|c|c|}
\hline Catalyst & $\begin{array}{l}\text { Catalyst mass } \\
(\mathrm{mg})\end{array}$ & $\mathrm{H}_{2} / \mathrm{CO}_{2}$ ratio & $\begin{array}{c}\text { WHSV } \\
\left(\mathbf{m L} \mathbf{g}_{\mathrm{cat}^{-1}} \mathbf{h}^{-1}\right)\end{array}$ & $\begin{array}{c}\text { Temperature } \\
\left({ }^{\circ} \mathrm{C}\right)\end{array}$ & Pressure (MPa) & Conversion (\%) & Selectivity (\%) \\
\hline $\begin{array}{l}2 \% \mathrm{Pt} / \mathrm{CeO}_{2} \text { (Goguet } \\
\text { et al., 2004b) }\end{array}$ & 40 & $4: 1$ & 300,000 & 290 & 0.1 & 21.7 & $\sim 100$ \\
\hline $\begin{array}{l}1 \% \mathrm{Ni} / \mathrm{CeO}_{2} \text { (Wang et al., } \\
2013 \mathrm{a})\end{array}$ & 50 & $1: 1$ & 120,000 & 400 & 0.1 & $\sim 4.5$ & $\sim 90$ \\
\hline $\begin{array}{l}5 \% \mathrm{Ru} / \mathrm{CeO}_{2} \text { (Panaritis } \\
\text { et al., 2018) }\end{array}$ & 50 & $1: 1$ & 120,000 & 350 & 0.1 & $\sim 16$ & $\sim 31$ \\
\hline $\begin{array}{l}\text { FeNi/CeZr (Sache et al., } \\
\text { 2020) }\end{array}$ & 250 & $4: 1$ & 24,000 & 350 & 0.1 & 13 & 60 \\
\hline $\begin{array}{l}5 \% \mathrm{Ru} / \mathrm{Sm}-\mathrm{CeO}_{2} \\
\text { (Panaritis et al., 2018) }\end{array}$ & 50 & $1: 1$ & 120,000 & 350 & 0.1 & $\sim 16$ & $\sim 69$ \\
\hline $\begin{array}{l}10 \% \mathrm{Co} / \mathrm{CeO}_{2} \text { (Wang } \\
\text { et al., 2013b) }\end{array}$ & 20 & $3: 1$ & 300,000 & 300 & 0.1 & 3.8 & 39.4 \\
\hline $\begin{array}{l}1 \% \mathrm{Pt} / \mathrm{TiO}_{2} \text { (Kim et al., } \\
2012 \mathrm{~b})\end{array}$ & 500 & $1: 1$ & 12,000 & 300 & 0.1 & $\sim 13$ & $\sim 100$ \\
\hline $\begin{array}{l}3.2 \% \mathrm{PtCo} / \mathrm{TiO}_{2} \text { (Kattel } \\
\text { et al., 2016b) }\end{array}$ & N/A & $2: 1$ & $\mathrm{~N} / \mathrm{A}$ & 300 & 0.1 & 8.2 & 98.8 \\
\hline $\begin{array}{l}0.2 \% \mathrm{Rh} / \mathrm{TiO}_{2} \text { (Matsubu } \\
\text { et al., 2015) }\end{array}$ & 15 & $4: 1$ & 40,000 & 200 & 0.1 & N/A & $\sim 14.5$ \\
\hline $\begin{array}{l}0.1 \% \mathrm{Ru} \mathrm{Al}_{2} \mathrm{O}_{3} \text { (Matsubu } \\
\text { et al., 2015) }\end{array}$ & 50 & $3: 1$ & 720,000 & 400 & 0.1 & $\sim 13$ & $\sim 80$ \\
\hline $\begin{array}{l}1 \% \mathrm{Pt} / \mathrm{Al}_{2} \mathrm{O}_{3} \text { (Kim et al., } \\
2012 \mathrm{~b})\end{array}$ & 500 & $1.43: 1$ & 12,000 & 300 & 0.1 & $\sim 5.8$ & $\sim 100$ \\
\hline $\begin{array}{l}\mathrm{PtCo} / \gamma-\mathrm{Al}_{2} \mathrm{O}_{3} \text { (Porosoff } \\
\text { and Chen, 2013) }\end{array}$ & N/A & $3: 1$ & $\mathrm{~N} / \mathrm{A}$ & 300 & $4 \times 10^{-3}$ & 10 & 89.4 \\
\hline $\begin{array}{l}20 \% \mathrm{Cu}-\mathrm{Ni} / \gamma-\mathrm{Al}_{2} \mathrm{O}_{3}(\mathrm{Liu} \\
\text { and Liu, 1999) }\end{array}$ & $\mathrm{N} / \mathrm{A}$ & $1: 1$ & 2,000 & 500 & 0.1 & 23.2 & 75.5 \\
\hline $\begin{array}{l}3.2 \% \mathrm{PtCo} / \mathrm{ZrO}_{2} \text { (Kattel } \\
\text { et al., 2016b) }\end{array}$ & N/A & $2: 1$ & N/A & 300 & 0.1 & 7.8 & 89.5 \\
\hline $\begin{array}{l}0.5 \% \mathrm{Pd} / \mathrm{La}_{2} \mathrm{O}_{3} / \mathrm{MWCNT} \\
\text { (Kwak et al., 2013a) }\end{array}$ & 50 & $3: 1$ & 72,000 & 400 & 0.1 & $\sim 20$ & $\sim 100$ \\
\hline $\begin{array}{l}\text { 0.5\%Pd/MWCNT (Kwak } \\
\text { et al., 2013a) }\end{array}$ & 50 & $3: 1$ & 72,000 & 400 & 0.1 & 0 & 0 \\
\hline $\begin{array}{l}10 \% \mathrm{Cu}-0.3 \% \mathrm{Fe} / \mathrm{SiO}_{2} \\
\text { (Chen et al., 2004) }\end{array}$ & 20 & $1: 1$ & 120,000 & 600 & 0.1 & $\sim 12$ & $\sim 100$ \\
\hline $\begin{array}{l}10 \% \mathrm{Cu} / \mathrm{SiO}_{2} \text { (Chen et al., } \\
2004 \text { ) }\end{array}$ & 20 & $1: 1$ & 120,000 & 600 & 0.1 & $\sim 8$ & $\sim 100$ \\
\hline $\begin{array}{l}0.3 \% \mathrm{Fe} / \mathrm{SiO}_{2} \text { (Chen et al., } \\
\text { 2004) }\end{array}$ & 20 & $1: 1$ & 120,000 & 600 & 0.1 & $\sim 2$ & $\sim 100$ \\
\hline $\begin{array}{l}1 \% \mathrm{NiO} / \mathrm{CeO}_{2} / \mathrm{SBA}-15 \text { (Lu } \\
\text { and Kawamoto, 2014) }\end{array}$ & 2,000 & $1: 1$ & 1,500 & 450 & 0.1 & $\sim 2.5$ & 100 \\
\hline $\begin{array}{l}\mathrm{ZnO} / \mathrm{Al}_{2} \mathrm{O}_{3}(\mathrm{Zn}: \mathrm{Al}=1: 2) \\
\text { (Park et al., 2001) }\end{array}$ & N/A & $3: 1$ & 15,000 & 400 & 0.1 & $\sim 3.4$ & $\sim 100$ \\
\hline
\end{tabular}


TABLE 1 | Continued

\begin{tabular}{|c|c|c|c|c|c|c|c|}
\hline Catalyst & $\begin{array}{l}\text { Catalyst mass } \\
(\mathrm{mg})\end{array}$ & $\mathrm{H}_{2} / \mathrm{CO}_{2}$ ratio & $\begin{array}{c}\text { WHSV } \\
\left(\mathrm{mL} \mathrm{g}_{\mathrm{cat}^{-1}} \mathrm{~h}^{-1}\right)\end{array}$ & $\begin{array}{c}\text { Temperature } \\
\left({ }^{\circ} \mathrm{C}\right)\end{array}$ & Pressure (MPa) & Conversion (\%) & Selectivity (\%) \\
\hline $\begin{array}{l}\text { 2D ( } \delta \text { )- }-\mathrm{MnO}_{2} \text { (He et al., } \\
\text { 2019) }\end{array}$ & 30 & $1: 1$ & 40,000 & 850 & 0.1 & 50 & 100 \\
\hline ZnO (Park et al., 2001) & $\mathrm{N} / \mathrm{A}$ & $3: 1$ & 15,000 & 400 & 0.1 & $\sim 2.6$ & $\sim 100$ \\
\hline $\mathrm{Al}_{2} \mathrm{O}_{3}$ (Park et al., 2001) & $\mathrm{N} / \mathrm{A}$ & $3: 1$ & 15,000 & 400 & 0.1 & 0 & 100 \\
\hline $\begin{array}{l}1 \% \mathrm{Cu} / \beta-\mathrm{Mo}_{2} \mathrm{C} \text { (Zhang } \\
\text { et al., 2016) }\end{array}$ & 20 & $2: 1$ & 300,000 & 350 & 0.1 & 11 & 40 \\
\hline $\begin{array}{l}7.5 \% \mathrm{Co}^{-\mathrm{Mo}_{2} \mathrm{C}} \text { (Porosoff } \\
\text { et al., 2014) }\end{array}$ & 100 & $2: 1$ & 36,000 & 300 & $1.07 \times 10^{-4}$ & 9.5 & $\sim 98.1$ \\
\hline $\begin{array}{l}\mathrm{Mo}_{2} \mathrm{C} \text { (Porosoff et al., } \\
\text { 2014) }\end{array}$ & 100 & $2: 1$ & 36,000 & 300 & $1.07 \times 10^{-4}$ & 8.7 & $\sim 93.5$ \\
\hline
\end{tabular}

into the metal surface, resulting in a weaker $\mathrm{CO}$ adsorption strength over the partially oxidized Ir nanoparticles and giving a near $100 \%$ selectivity toward CO compared with that over the corresponding metallic Ir. Therefore, modulation of the chemical state of the metal species by the SMSI is more important for the regulation of the observed CO selectivity in the RWGSR ( $\mathrm{Li}$ et al., 2017). For the $\mathrm{Cu} / \mathrm{CeO}_{2}$ catalyst, the $\mathrm{Ce}^{3+}-\mathrm{O}_{\mathrm{v}}-\mathrm{Cu}^{0}$ and $\mathrm{Cu}^{0}-\mathrm{CeO}_{2-\delta}$ interface structures can be generated by the electron transfer from $\mathrm{Cu}$ to $\mathrm{Ce}$ on its surface through SMSI effect, which can boost the adsorption and activation performance of reactant $\mathrm{CO}_{2}$ and $\mathrm{H}_{2}$ molecules for RWGSR (Zhou et al., 2020). In the simulation of catalytic $\mathrm{CO}_{2}$ reduction by Pd-decorated silicon-hydride nanosheets (Pd@SiNS), the direct SMSI between the $\mathrm{Pd}$ nanoparticle and the $\mathrm{Si}$ nanosheet causes $\mathrm{H}$ transfer from the Pd to the oxidized SiNS surface, which may occur repeatedly by two mechanisms. First, an $\mathrm{H}$ atom adsorbed on the Pd nanoparticle interacts with a surface Si-O-Si and creates a $\mathrm{Si}-\mathrm{OH}$; second, another $\mathrm{H}$ from the $\mathrm{Pd}$ nanoparticle forms a bond with the $\mathrm{Si}-\mathrm{OH}$, which leads to desorption of the $\mathrm{H}_{2} \mathrm{O}$, creating a surface radical, thereby enabling a catalytic cycle. Furthermore, the strain induced in the SiNS by the Si-O-Si bonds enhances the reactivity of the oxidized SiNS surface toward the transformation of $\mathrm{CO}_{2}$ to $\mathrm{CO}$ under mild conditions (Qian et al., 2019). In the context of $\mathrm{Mo}_{2} \mathrm{C}$-supported Co catalysts, the SMSI effect facilitates the formation of the amorphous $\mathrm{CoMoC}_{y} \mathrm{O}_{z}$ phase formed during the $\mathrm{CO}_{2}$ hydrogenation, in which the Co with a positive charge is identified as the critical active site that dissociates $\mathrm{CH}_{4}$ to $\mathrm{CO}$. Therefore, the addition of $7.5 \%$ $\mathrm{Co}$ to $\mathrm{Mo}_{2} \mathrm{C}$ leads to an increase in conversion from 8.7 to 9.5\%, while the $\mathrm{CO}: \mathrm{CH}_{4}$ ratio increases from 15 to 51 (Porosoff et al., 2014). When $\mathrm{Cu}$ is added to the $\beta-\mathrm{Mo}_{2} \mathrm{C}$ support during the preparation process, the SMSI effect not only promotes the dispersion of supported copper and prevents the aggregation of $\mathrm{Cu}$ particles but also enables a portion of the electrons to transfer from $\mathrm{Cu}$ to $\mathrm{Mo}_{2} \mathrm{C}$ so that the $\mathrm{Cu}^{+}$and $\mathrm{Cu}^{0}$ species coexist in the $\mathrm{Cu} / \beta-\mathrm{Mo}_{2} \mathrm{C}$ catalyst. Its modulated electronic structure makes the highly dispersed $\mathrm{Cu}$ species more active in the $\mathrm{CO}_{2}$ activation and accelerates the $\mathrm{CO}^{*}$ desorption in the following transformation reactions, which accounts for its excellent activity in the RWGSR, as depicted in Figure 4 (Zhang et al., 2016).

\section{Metal Size Effect}

The RWGSR is considered structure sensitive for supported catalysts, of which the intermediate dissociation pathway associated with $\mathrm{H}$ assistance is substantially dependent on the size of the anchored metal active sties and thus exerts an influence on the CO selectivity of the RWGSR (Chen et al., 2017a).

Multiple studies have been conducted to study the size effect of metal sites relative to CO selectivity in supported noble metal catalysts. The metal active sites (i.e., Pt, Pd, Ru) dispersed at an atomic level contribute more to the $\mathrm{CO}$ product compared to metal clusters at a $3 \mathrm{D}$ level. This phenomenon is a consequence of the absence of larger metals clusters in which the initially formed $\mathrm{CO}_{\mathrm{ad}}$ can be further activated during the continuous reaction (Kwak et al., 2013a,b; Wang et al., 2016a; Chen et al., 2017a). In addition, the Pd sites that slightly retain the CO surface species formed from the formates and other intermediates are more prevalent on the surface of the smaller Pd particles and thus exhibit a higher selectivity toward the $\mathrm{CO}$ product. In contrast, the larger Pd particles, due to a higher population of terrace sites in which it is easier to form multi-bound $\mathrm{CO}$ and dissociated $\mathrm{H}_{2}$ bound in the vicinity of $\mathrm{CO}$, reveal a stronger interaction with $\mathrm{CO}$. These stable $\mathrm{CO}$ species are mainly in multi-bound forms and act as the direct intermediates to $\mathrm{CH}_{4}$ (Wang et al., 2015, 2017). Matsubu et al. have utilized DRIFTS with known site-specific extinction coefficients to quantify the fraction of Rh sites residing as atomically dispersed isolated sites $\left(\mathrm{Rh}_{\mathrm{iso}}\right)$, as well as $\mathrm{Rh}$ sites on the surface of $\mathrm{Rh}$ nanoparticles $\left(\mathrm{Rh}_{\mathrm{NP}}\right)$ for a series of $\mathrm{TiO}_{2}$ supported $\mathrm{Rh}$ catalysts. The reaction conditioninduced disintegration of $\mathrm{Rh}_{\mathrm{NP}}$, which form the $\mathrm{Rh}_{\text {iso }}$ active sites, have been observed to control the CO selectivity of the RWGSR (Matsubu et al., 2015). Furthermore, we have determined that the difference between the desorption energy and dissociation barrier of metal carbonyls is a critical factor for determining the $\mathrm{CO}$ selectivity of the RWGSR by combining DFT calculations and experiments, as shown in Figure 5. Specifically, narrowing the size of the Ir active sites by decreasing the Ir loading over $\mathrm{Ir} / \mathrm{TiO}{ }_{2}$ catalysts can hinder the carbonyl dissociation but improve the CO desorption, giving rise to CO selectivity (Chen et al., 2017a).

For supported non-noble metal catalysts, significant efforts on Ni-based catalysts have also shown that smaller anchored $\mathrm{Ni}$ active sites are beneficial to produce $\mathrm{CO}$ in the RWGSR 


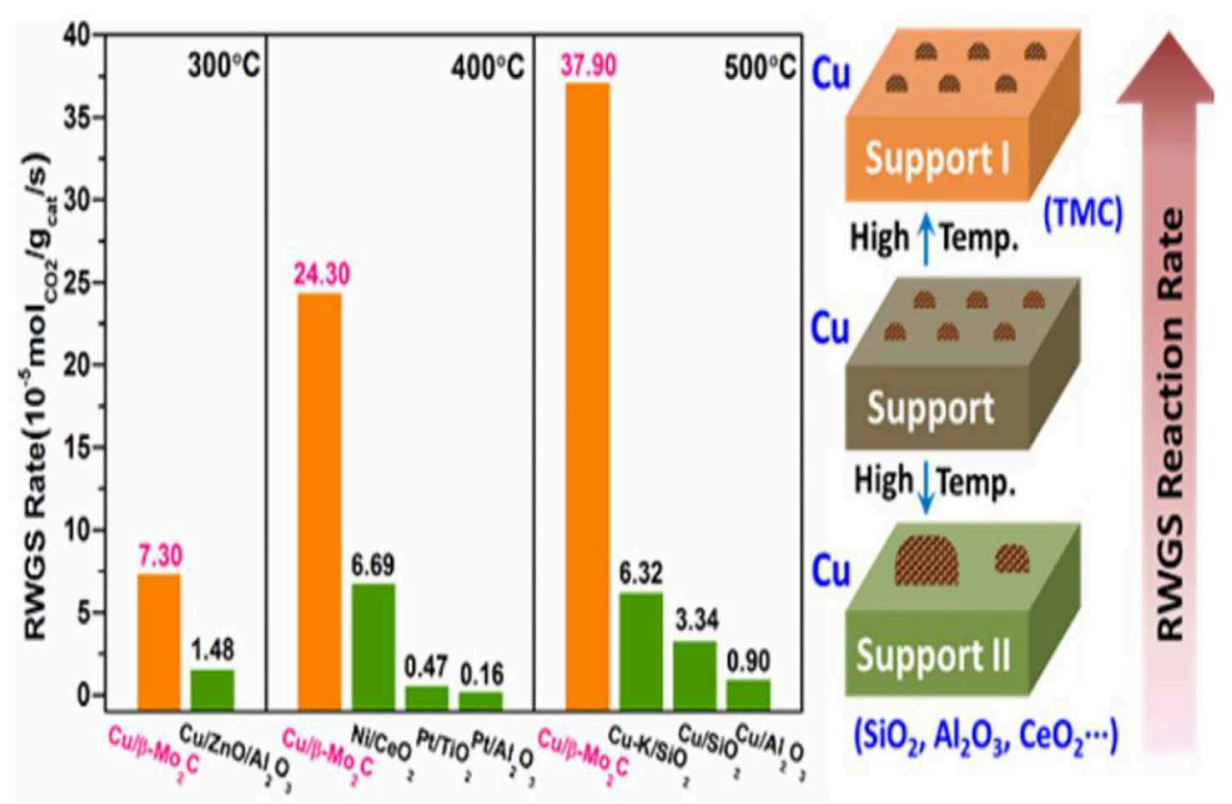

FIGURE 4 | RWGSR rate and SMSI effect of $\mathrm{Cu} / \beta-\mathrm{Mo}_{2} \mathrm{C}$ and reference catalysts. Reprinted with permission from Zhang et al. (2016). Copyright (2017) American Chemical Society.

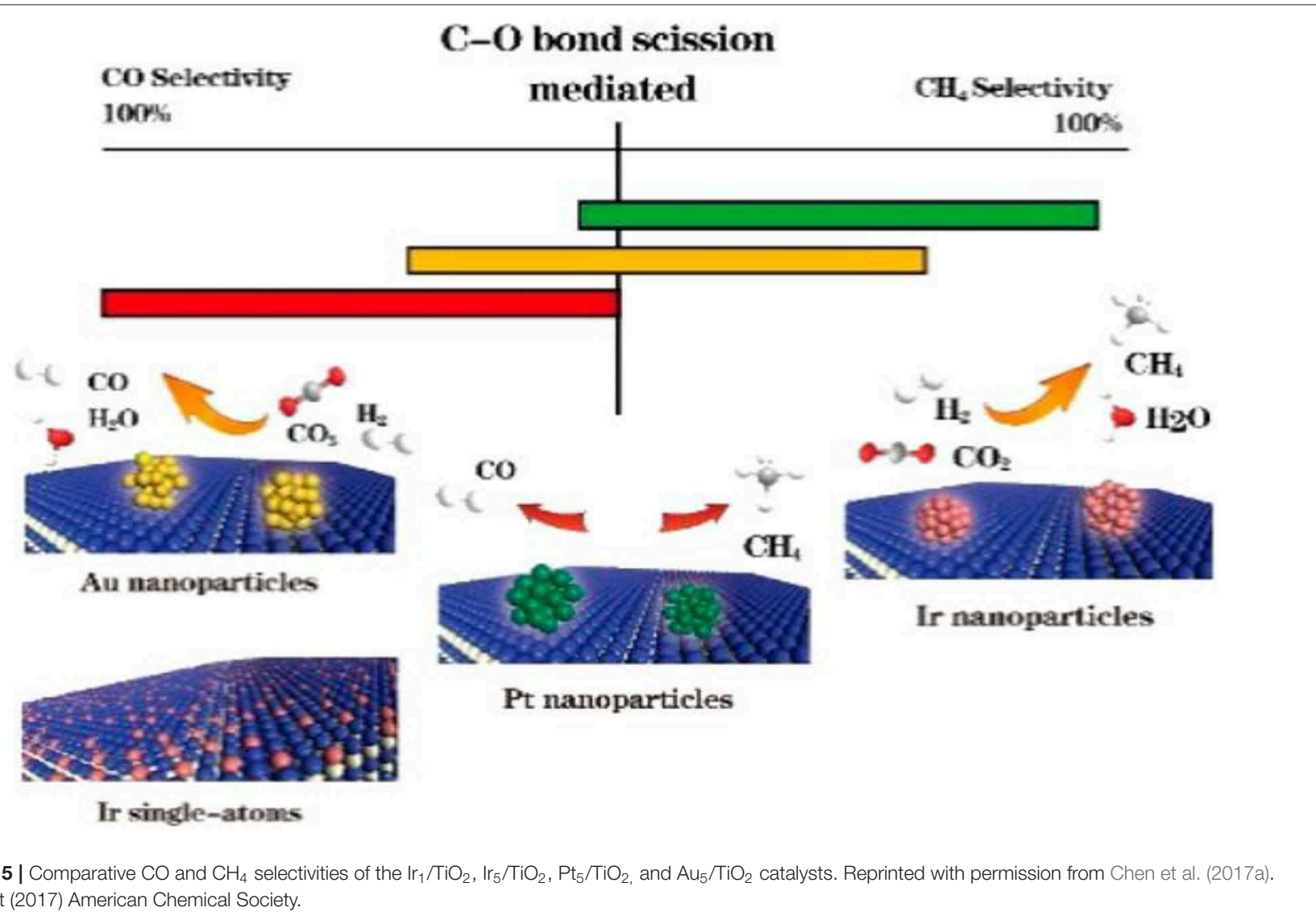


(Wang et al., 2013a,d; Lu and Kawamoto, 2014). The consecutive pathway is favored on small $\mathrm{Ni}$ particles, which is attributed to low $\mathrm{H}_{2}$ coverage on the $\mathrm{Ni}$ surface, thus leading to the dissociation of the intermediates and high CO selectivity. Whereas the RWGSR on large Ni particles may be controlled by mixed consecutive and parallel pathways, it increases the likelihood that the intermediates will be competitively hydrogenated to $\mathrm{CO}$ or $\mathrm{CH}_{4}$ as part of a parallel reaction pathway (Wu et al., 2015). Millet et al. reported on the activation of $\mathrm{CO}_{2}$ on $\mathrm{Ni}$ single-atom catalysts that are synthesized using a solid solution approach by controlled substitution of 1-10 atom \% of $\mathrm{Mg}^{2+}$ by $\mathrm{Ni}^{2+}$ inside the $\mathrm{MgO}$ structure. The $\mathrm{Ni}$ atoms are preferentially located on the surface of the $\mathrm{MgO}$ and, as predicted by hybrid-functional calculations, favor the lowcoordinated sites, where they can reduce the strength of the $\mathrm{CO}_{2}$ binding and promote $\mathrm{H}_{2}$ dissociation. Thus, the $\mathrm{Ni}$ atoms are active for $\mathrm{CO}_{2}$ conversion through the RWGSR but are unable to conduct its further hydrogenation to $\mathrm{CH}_{4}$, for which Ni clusters are needed (Millet et al., 2019).

\section{Shape and Crystal Face Effect}

RWGSR activities are also significantly depending on the shape and exposed crystal face of catalysts because they can determine the virtual adsorption energy and desorption energy of intermediates in the reaction process (Liu et al., 2019).

Up to now, abundant efforts have been dedicated to study the effect of surface structure of Cu-based catalysts on RWGSR performance. Through the simulation of the adsorption of $\mathrm{CO}_{2}$, $\mathrm{H}_{2}, \mathrm{H}, \mathrm{O}, \mathrm{OH}, \mathrm{CO}$, and $\mathrm{H}_{2} \mathrm{O}$ on the $\mathrm{Cu}(h k l)$ surfaces at low coverage, it has been demonstrated that the trend in the calculated activation barriers for the reaction is $\mathrm{CO}_{2}$ dissociative adsorption (namely $\mathrm{CO}_{2, \mathrm{~g}} \mathrm{COs}+\mathrm{Os}$ ) follows the order of $\mathrm{Cu}(110)<\mathrm{Cu}(100)<\mathrm{Cu}(111)$, suggesting that the most efficient crystal surface for catalyzing RWGSR by copper is $\mathrm{Cu}(110)$, and the more densely packed $\mathrm{Cu}(111)$ surface is the least active among the $\mathrm{Cu}(h k l)$ surfaces studied here (Nakamura et al., 1998; Wang et al., 2003; Wang and Nakamura, 2010). When the $\mathrm{Cu}$ particles are doped onto the $\mathrm{CeO}_{2}$-Nanaorod and $\mathrm{CeO}_{2}$ Nanosphere surfaces, respectively, which can be marked as $\mathrm{Cu} / \mathrm{CeO}_{2}-\mathrm{NR}(111)$ and $\mathrm{Cu} / \mathrm{CeO}_{2}-\mathrm{NS}(110)$, by comparation, the $\mathrm{Cu} / \mathrm{CeO}_{2}-\mathrm{NR}$ displays the higher RWGSR activity. This is mainly because that the $\mathrm{CO}_{2}$ dissociative activation and the formation of active bidentate carbonate and formate intermediates over $\mathrm{CeO}_{2}$ (110) become more feasible (Kovacevic et al., 2016; Lin et al., 2018b). Furthermore, self-assembled $\mathrm{CeO}_{2}$ with $3 \mathrm{D}$ hollow nanosphere, nanoparticle, and nanocube morphologies are used to support $\mathrm{Cu}$ particles, which can be denoted as $\mathrm{Cu} / \mathrm{CeO}_{2}$ hs(111), $\mathrm{Cu} / \mathrm{CeO}_{2}-\mathrm{np}(111)$, and $\mathrm{Cu} / \mathrm{CeO}_{2}-\mathrm{nc}(200)$, respectively. Thereinto, the $\mathrm{Cu} / \mathrm{CeO}_{2}-\mathrm{hs}(111)$ presents the best catalytic RWGSR performance among these as-prepared catalysts due to its high concentration of active oxygen vacancies sites (Zhang et al., 2020). For $\mathrm{PtCo} / \mathrm{TiO}_{2}(110)$, ${ }^{*} \mathrm{HCOO}$ is formed as an intermediate, which may eventually produce $\mathrm{CO}$, whereas for $\mathrm{PtCo} / \mathrm{CeO}_{2}(110)$, the aside from the route that proceeds via ${ }^{*} \mathrm{HCOO}$, a pathway via a ${ }^{*} \mathrm{CH}_{3} \mathrm{O}$ intermediate is operating in parallel, which likely leads to the formation of $\mathrm{CH}_{4}$. Moreover, DFT calculation demonstrates that the adsorption of $\mathrm{CO}_{2}$ is stronger at the $\mathrm{Ni}_{\mathrm{n}} / \mathrm{YSZ}(111)(n=4-7,10$, and 20) interface than on the clean YSZ(111) between the Ni clusters and the YSZ(111) surface, which facilitates the transformation of $\mathrm{CO}_{2}$ to $\mathrm{CO}$ (CadiEssadek et al., 2018). For $\mathrm{Cu} @ \mathrm{Mo}_{2} \mathrm{C}(001)$ and $\mathrm{Cu}_{4} @ \mathrm{Mo}_{2} \mathrm{C}(001)$ surfaces, although the dissociative adsorption of $\mathrm{H}_{2}$ on these two surface is barrier-free and highly exothermic, the activation barrier of carboxyl formation or $\mathrm{C}-\mathrm{O}$ bond scission as a ratelimiting step on the $\mathrm{Cu}_{4} @ \mathrm{Mo}_{2} \mathrm{C}(001)$ surfaces is smaller, and the desorption of $\mathrm{CO}$ at the $\mathrm{Cu}$ site needs less heat than Mo site, thereby accelerating $\mathrm{CO}_{2}$ conversion in RWGSR (Chen and Cheng, 2002).

\section{Bimetallic Effect}

The behavior of a catalyst is modulated by its interaction with other catalyst components, such as a second metal, which influences it through electronic interactions, generates interfacial active sites, or is directly involved in the reaction by bonding to reactants or intermediates (Liu and Liu, 1999; Liu et al., 2015). Therefore, supported bimetallic catalysts have been extensively used for the RWGSR due to their tuning catalytic activity that may be achieved by two metals working synergistically.

The existence of $\mathrm{Mo}$ in the structure of the $\mathrm{Fe}-\mathrm{Mo} / \mathrm{Al}_{2} \mathrm{O}_{3}$ catalyst enhances its catalytic performance for the RWGSR due to the electronic effect, which transfers electrons from $\mathrm{Fe}$ to Mo and leads to an electron-deficient state of the Fe species, in which it is not helpful for CO adsorption and hence inhibits the continuous hydrogenation of the intermediates (Kharaji et al., 2013; Panaritis et al., 2018). It is reasonable for the $\mathrm{Ni}$ species with the electron deficient state to possess high catalytic performance for RWGSR when $\mathrm{Ni}$ is added as a second metal component to the $\mathrm{Mo} / \mathrm{Al}_{2} \mathrm{O}_{3}$ catalyst (Kharaji et al., 2014). As for $\mathrm{RuNi} / \mathrm{CeZr}$ catalyst, the addition of $\mathrm{Ru}$ enhances the $\mathrm{Ni}$ reducibility and leads to greater $\mathrm{Ni}$ dispersion on the catalyst surface, thus promoting overall activity and CO selectivity for the RWGSR (Sache et al., 2020). Typically, MOF-74 plays a role in helping adsorb and deliver electrons, whereas the low amount of Au@Pd NPs in Au@Pd@MOF-74 results in the poor photon adsorption strength of the Au@Pd active sites. Based on this feature, the core-shell Au@Pd@MOF-74 nanostructure is more propitious to generate $\mathrm{CO}$ than MOF-74 in the RWGSR because $\mathrm{CO}$ generation is a two-electron reaction, while $\mathrm{CH}_{4}$ generation requires eight electrons; thus, it is more difficult to produce $\mathrm{CH}_{4}$ (Han et al., 2019). Because of the functional characteristics of Au@Pd nanoparticles, the Pt/Au@Pd@UIO-66 catalyst is synthesized to improve its catalytic activity in the RWGSR, as shown in Figure 6. In this system, the core-shell monodispersed Au@Pd nanosphere is encapsulated in the UIO-66 to control its morphology and impart nanoparticle functionality. Additionally, the microporous nature of the UIO-66 assists the adsorption of the Pt nanoparticles, which enhances the interaction between them, favoring the formation of isolated and well-dispersed Pt nanoparticle active sites. This advanced architecture results in excellent catalytic activity and CO selectivity for the RWGSR, and the concept of inserting nanoparticles into microporous MOFs will revolutionize future industrial applications (Zheng et al., 2018). DFT calculations 


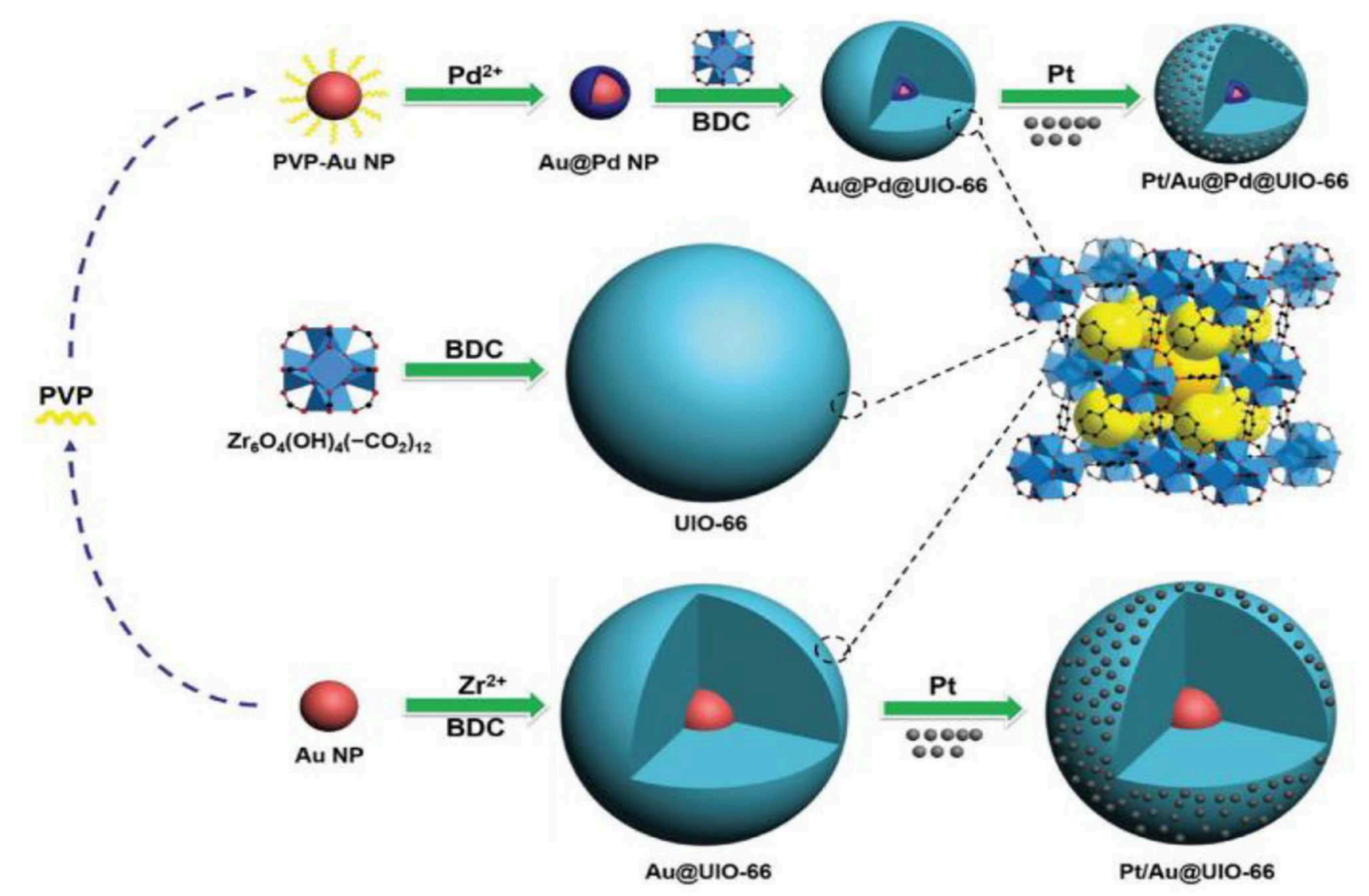

FIGURE 6 | Synthetic route for the production of Au@Pd NPs and other nanocomposites. Reprinted with permission from Zheng et al. (2018). Copyright (2017) Wiley-VCH.

indicate that the catalytic behavior of a $\mathrm{Cu}_{12} \mathrm{TM}(\mathrm{TM}=\mathrm{Co}$, $\mathrm{Rh}, \mathrm{Ir}, \mathrm{Ni}, \mathrm{Pd}, \mathrm{Ag}, \mathrm{Au}$ ) bimetallic nanocluster in the RWGSR is dependent on the position of the d-band center. In general, the closer the d-band center is to the Fermi level of these catalysts, the greater is the $\mathrm{CO}_{2}$ adsorption energy, and the smaller is the $\mathrm{C}-\mathrm{O}$ bond dissociation barrier. Therefore, $\mathrm{Cu}_{12} \mathrm{Co}$ delivers better catalytic activity for the RWGSR, with a TOF value of $8.96^{*} 10^{-13} \mathrm{~s}^{-1}$, than do the $\mathrm{Cu}_{13}$ and $\mathrm{Cu}_{12} \mathrm{TM}$ bimetallic systems, due to its d-center value of $-0.547 \mathrm{eV}$, which is higher than that of the other two systems (Zhang and Guo, 2018). Furthermore, for $\gamma-\mathrm{Al}_{2} \mathrm{O}_{3}$ - and $\mathrm{CeO}_{2}$-supported $\mathrm{Co}$ catalysts, with the addition of $\mathrm{Pt}$ as the second component, the values of the d-band center move from the Fermi level toward more negative values, which prevents the excessive hydrogenation of the $\mathrm{C}-\mathrm{O}$ bond of the $\mathrm{CO}_{2}$ molecule and thereby increases the CO selectivity of the RWGSR (Porosoff and Chen, 2013). In addition, the deposition of $\mathrm{Mo}$ onto $\mathrm{Au} / \mathrm{SiO}_{2}$ catalyst generates new $\mathrm{Au} / \mathrm{MoO}_{\mathrm{x}}$ interfacial sites since it preferentially occurs on undercoordinated $\mathrm{Au}$ sites. The heat of $\mathrm{CO}$ adsorption $\left(\Delta \mathrm{H}_{\mathrm{ads}}\right)$ for the $\mathrm{Au} / \mathrm{MoO}_{\mathrm{x}}$ sites is $33 \mathrm{~kJ} \mathrm{~mol}^{-1}$, considerably lower than that of the $\mathrm{Au}^{0}$ sites, indicating that these interfacial sites are more selective than the $\mathrm{Au}^{0}$ sites for the RWGSR (Carrasquillo-Flores et al., 2015). Similarly, the Cu/Fe interfacial active sites are generated after introduction of additional $\mathrm{Fe}$ into the $\mathrm{Cu} / \mathrm{SiO}_{2}$ catalyst, on which the formation of the $\mathrm{Fe}-\mathrm{Cu}$ bond also prevents $\mathrm{Cu}$ from being sintered and oxidized during the RWGSR (Chen et al., 2004). Moreover, the addition of $\mathrm{Cu}$ to the Mo/FAU catalyst results in an improvement in the reducibility of $\mathrm{MoO}_{3}$. Therefore, the $\mathrm{Mo}(0.8) \mathrm{Cu}(0.2) / \mathrm{FAU}$ catalyst, which contains co-supported $\mathrm{Mo}-\mathrm{Cu}$ at an atomic ratio of $4: 1$, exhibits the higher CO yield of $18.5 \%$ and selectivity of $99 \%$ compared with the supported Mo catalyst for the RWGSR with the feed gas $\left(\mathrm{H}_{2}: \mathrm{CO}_{2}=1: 1\right)$ at atmosphere pressure and $773 \mathrm{~K}$ (Okemoto et al., 2020). The bulk $\mathrm{Pt}_{3} \mathrm{Ni}$ intermetallic parent compound is formed selectively over the Pt-Ni bimetallic catalysts supported on mesoporous silica, which is related to the thermodynamics of the phase equilibria with a metal silicate that precludes the formation of more Ni-rich intermetallics during the operando conditions of the RWGSR, as shown in Figure 7. This proposed intermetallic structure for these $\sim 1 \mathrm{~nm}$ supported clusters, shows a surface/interfacial speciation of the $\mathrm{Ni}$ in which only heterometallic Pt$\mathrm{Ni}$ interactions are present in an atomic arrangement within the catalytically active bimetallic sites, which afford exceptionally high activity and CO selectivity in the RWGSR (Liu et al., 2018). 


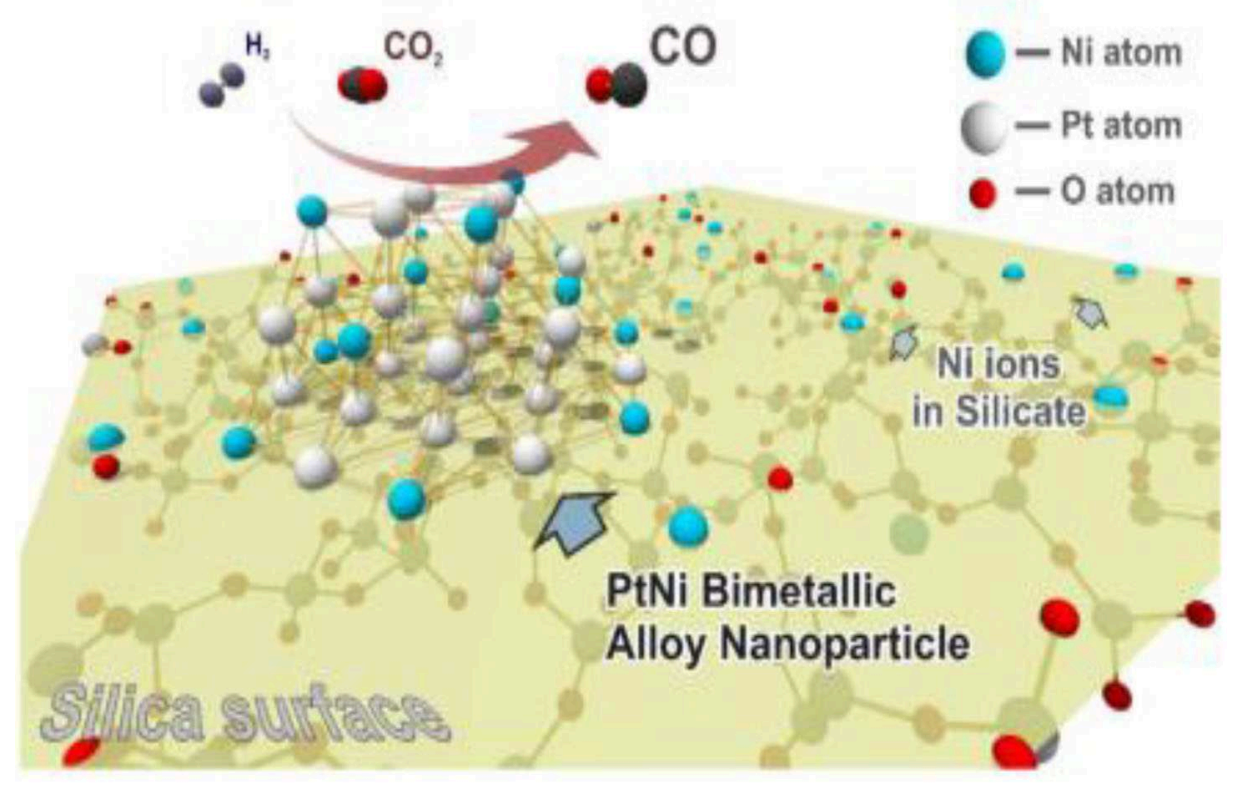

FIGURE 7 | Schematic model of the PtNi/SBA-15 catalyst. Reprinted with permission from Liu et al. (2018). Copyright (2018) American Chemical Society.

\section{Alkali Promoter Effect}

For supported heterogeneous catalysts, alkali metal components are typically introduced as promoters to increase the amount of adsorption sites and mediate the adsorption strength of the reactants and intermediates on the "inert support" (Li et al., 1998; Gálvez et al., 2013; Obalová et al., 2013; Connor and Holland, 2017; Pacultová et al., 2017). For instance, the addition of alkali metal promoters is crucial for industrial catalysts substantially applied in the Fisher-Tropsch synthesis (Mirzaei et al., 2006; Okabe et al., 2007; Feyzi et al., 2011; Cosultchi et al., 2012) and ammonia synthesis (Shimoda et al., 2017; Lin et al., 2018a; Jafari et al., 2019; Rogowski, 2019; Zhou et al., 2019). In the field of RWGSRs, abundant studies have shown that $\mathrm{K}$ and other promoter additives are essential for some supported catalysts to acquire the expected CO product (Arunajatesan et al., 2007).

The highly $\mathrm{K}$-promoted $\mathrm{Fe} / \mathrm{Al}_{2} \mathrm{O}_{3}$ and $\mathrm{Cu} / \mathrm{SiO}_{2}$ catalysts give much higher $\mathrm{CO}$ formation rates than do their counterparts in the RWGSR mainly because the addition of $\mathrm{K}$ introduces abundant weak, medium, and strong basic sites, which helps to adsorb/activate $\mathrm{CO}_{2}$ and further converts the $\mathrm{CO}_{2}$ to $\mathrm{CO}$ through reaction (Choi et al., 1996; Chen et al., 2003). For the $\mathrm{Ni} / \mathrm{Al}_{2} \mathrm{O}_{3}$ catalyst, carbonates are the main intermediates, decomposition of which to CO is relatively difficult. However, via modification of this catalyst with a strong base such $\mathrm{KOH}$, the formates rather than the carbonate forms as the main intermediate, which strongly absorbs on the surface of the $\mathrm{Ni}-\mathrm{KOH} / \mathrm{Al}_{2} \mathrm{O}_{3}$ catalyst, contributes to $\mathrm{CO}$ formation and hinders further hydrogenation of the $\mathrm{CO}$ to $\mathrm{CH}_{4}$ through $\mathrm{C}-\mathrm{O}$ bond scission (Zhang et al., 2019a). Furthermore, it is demonstrated that the introduction of alkali promoter $(\mathrm{K}, \mathrm{Mg})$ by co-impregnation technique enhance the dispersity of $\mathrm{Ni}$ active species on the $\mathrm{Al}_{2} \mathrm{O}_{3}$, thus increasing the RWGSR performance (Ranjabar et al., 2019). The addition of
$\mathrm{K}$ promoter leads to an electron transfer from $\mathrm{Pt}$ to $\mathrm{O}$ in $\mathrm{KO}_{\mathrm{x}}$ species, resulting in the generation of interfacial active sites over the $\mathrm{Pt} /$ mutille catalyst, which is proposed to be more responsible for the production of CO (Liang et al., 2017). Similarly, the K promoter acts as a reducing agent relative to the Fe metal, and the observed increase in the ratio of the $\mathrm{Fe}^{2+} / \mathrm{Fe}^{3+}$ ions over the $\mathrm{BaFe}$-hexaaluminates after the $\mathrm{K}$ addition reflects the increasing concentration of reduced $\mathrm{Fe}^{2+}$ ions in the hexaaluminate lattice, which is accompanied by the appearance of oxygen vacancies due to the cleavage of one of the neighboring Fe-O-M $(\mathrm{M}=\mathrm{Al}, \mathrm{Ba})$ bonds in the first coordination sphere of Fe ions. These vacancies play a role in the sites for $\mathrm{CO}_{2}$ adsorption forming monodentate surface carbonates followed by redox transformation evolving $\mathrm{CO}$ and leaving the second oxygen bonded to the $\mathrm{Fe}^{3+}$ ion (Wang et al., 2013b,c; Utsis et al., 2018). The results of DFT calculations demonstrate that the $\mathrm{K}$ adatom greatly stabilizes the adsorption of all oxygenate intermediates through direct K-O bonding formation on K-modified $\mathrm{Cu}(111)$ and $\mathrm{Cu}(110)$ surfaces, thus promoting $\mathrm{CO}_{2}$ dissociation in the RWGSR. In general, the different promoting effects of alkali metals on $\mathrm{CO}_{2}$ dissociation are due to their electronegativities, which induce different work function changes and surface dipole moments. Correspondingly, the promoting effects on $\mathrm{CO}_{2}$ dissociation induced by alkali metals increase in the order of $\mathrm{Na}<\mathrm{K}<\mathrm{Rb}$ $<$ Cs, while the electronegativity of various alkali metals decreases in the order of $\mathrm{Na}>\mathrm{K}>\mathrm{Rb}>\mathrm{Cs}$ (Wang and Wang, 2019). In accordance with the above effects, the electronegative character facilitates the electronic transfer from $\mathrm{Cs}$ to $\mathrm{Mo}$ and $\mathrm{Fe}$ and leads to an electronically rich surface, which favors the selectivity toward $\mathrm{CO}$ over the corresponding catalysts (Pastor-Pérez et al., 2018; Zhang et al., 2019b). For the $\mathrm{WC} / \gamma-\mathrm{Al}_{2} \mathrm{O}_{3}$ catalyst, the addition of the $\mathrm{K}$ promoter not only has a structural effect 
to promote the dispersion of the WC species across the high surface area support but also can serve as electronic promotion to strengthen $\mathrm{CO}$ and $\mathrm{CO}_{2}$ adsorption while weakening $\mathrm{H}_{2}$ adsorption, which is therefore hypothesized to result in a lower $\mathrm{H}_{2} / \mathrm{Co}_{\mathrm{x}}$ on the catalyst surface, thus inhibiting hydrogenation activity for $\mathrm{CH}_{4}$ and accelerating the generation of $\mathrm{CO}$ via the RWGSR (Morse et al., 2020). Specifically, our studies have systematically investigated the effect of $\mathrm{K}$ promoter on the activities and selectivities of zeolite L-supported Pt catalysts for the RWGSR, as shown in Figure 8. This study concluded that an additive $\mathrm{K}$ promoter not only alters the work function of Pt through their interaction but also forms $\mathrm{Pt}-\mathrm{O}(\mathrm{OH})-\mathrm{K}$ interfacial sites. In addition, the electronic properties of Pt$\mathrm{O}(\mathrm{OH})-\mathrm{K}$ sites, with a charge transfer from the Pt surface to the adjacent $\mathrm{O}$ in $\mathrm{KO}_{\mathrm{x}}$, facilitate the formation of formate intermediates and desorption of the CO. However, with excessive addition of $\mathrm{K}$, the access of the reactants to the Pt surface and interface is tightly blocked. Thus, the activity of the RWGSR is significantly promoted by the controlled addition of $\mathrm{K}$ promoter (Yang et al., 2017).

\section{Oxide Catalysts}

Reducible transition oxides are intensively employed in RWGSR catalysts due to their relative abundance and their OSC, which is the ability to reversibly store and release oxygen while formally switching the valence state of the metal ion in its own structure under a $\mathrm{CO}_{2} / \mathrm{H}_{2}$ atmosphere (Reddy et al., 2010; Dong et al., 2012; Yao et al., 2013). The $\mathrm{O}$ atom can be deprived of $\mathrm{H}_{2}$ in the oxide lattice to generate surface oxygen vacancies, which are much more favorable to the generation of $\mathrm{CO}$ rather than $\mathrm{CH}_{4}$, because the oxygen from the $\mathrm{C}-\mathrm{O}$ bond cleavage of the $\mathrm{CO}_{2}$ molecule can be accommodated, but this leads to unsatisfactory catalytic activity and thermal stability (Katta et al., 2010; Ahn et al., 2012; Graciani et al., 2014). Normally, the additional introduction of heteroatoms into the oxides leads to the formation of spinel, solid solution, and perovskite-type oxides, and their ultra-stable structure is conductive to reversible oxygen donor-acceptor over oxygen vacancies sites, which thus effectively overcome the disadvantages of pure oxides as RWGSR catalysts (Ringuedẽ and Fouletier, 2001; Royer et al., 2005).

$\mathrm{ZnO}$-based oxides are preferentially utilized to catalyze the RWGSR during the CAMARE process due to its ease of formation of metal composite oxides with high stability and specific activity (Li et al., 2002; Schmale et al., 2013). Nonetheless, $\mathrm{ZnO}$-based oxide catalysts are vulnerable to the reduction of $\mathrm{ZnO}$ to $\mathrm{Zn}$ metal and therefore the loss of $\mathrm{ZnO}$ active components when exposed to high thermal reaction conditions, which contributes to their catalytic deactivation (Park et al., 2001). The formation of the spinel structure of the $\mathrm{ZnAl}_{2} \mathrm{O}_{4}$ phase by addition of $\mathrm{Al}_{2} \mathrm{O}_{3}$ to the $\mathrm{ZnO}$ catalyst can cause resistance to its catalytic deactivation in the RWGSR (Joo and Jung, 2003). Similarly, when $\mathrm{Fe}_{2} \mathrm{O}_{3}$ is substituted by $\mathrm{ZnO}$ over the $\mathrm{Fe}_{2} \mathrm{O}_{3} / \mathrm{Cr}_{2} \mathrm{O}_{3}$ catalyst, the corresponding $\mathrm{ZnCr}_{2} \mathrm{O}_{4}$ phase is formed and thus becomes stable (Park et al., 2000). In the synthetic process of the $\mathrm{ZnZrO}_{\mathrm{x}}$ mixed oxide, the substitution of the $\mathrm{Zr}$ in the first layers of the $m-\mathrm{ZrO}_{2}$ lattice with $\mathrm{Zn}$ causes the formation of a surface solution $\left(\mathrm{Zn}_{\mathrm{x}} \mathrm{Zr}_{1-\mathrm{x}} \mathrm{O}_{2-\mathrm{y}}\right)$, which generates oxygen vacancies and improves its stability, reducibility, and oxygen mobility, thus increasing the $\mathrm{CO}_{2}$ conversion in the RWGSR (Silva-Calpa et al., 2016).

The widespread application of $\mathrm{CeO}_{2}$-based oxide in RWGSR catalysts is mainly due to its high OSC, which is inextricably correlated with the catalytic activity (Masui et al., 1997; Wang and Liu, 2018). Both the manipulation of the $\mathrm{CeO}_{2}$ shape with emphasis on tuning its fraction of reactive crystal planes and the doping $\mathrm{CeO}_{2}$ with heterocations to alter its structure and chemical properties are effective strategies to obtain a superior OSC (Sun et al., 2012; Zhou and Li, 2012). Considering their distinct morphologies (particles, rods, and cubes), the higher activity of $\mathrm{CeO}_{2}$ cubes in the RWGSR is due to the superior inherent reactivity of the $\mathrm{CeO}_{2}(100)$ crystal planes enclosing the cubes, contrary to the less inherently reactive $\mathrm{CeO}_{2}$ (111) facets enclosing the rods and particles in the RWGSR (Kovacevic et al., 2016). The $\mathrm{CeO}_{2}$ lattice distortion caused by the incorporation of heterocations such as $\mathrm{Zn}$ increases the oxygen vacancy defects and thus accelerates the mobility of the oxygen ions, leading to a higher OSC, thus markedly enhancing its catalytic activity in the RWGSR (Lin et al., 2015; Wenzel et al., 2017). In addition, either $\mathrm{Ce}_{0.75} \mathrm{Zr}_{0.25} \mathrm{O}_{2}$ or $\mathrm{Ce}_{0.75} \mathrm{Zr}_{0.5} \mathrm{O}_{2}$ solid solution can be formed by the addition of $\mathrm{Zr}$ to the $\mathrm{CeO}_{2}$ lattice, increasing its ability to generate oxygen vacancies and, more importantly, promoting its thermal stability, which is a very promising aspect of catalytic systems employed in reactions in which the RWGSR is one of the steps in the processes that generate hydrocarbons from $\mathrm{CO}_{2}$ (Zonetti et al., 2014; Wenzel et al., 2018).

The adsorption of $\mathrm{CO}_{2}$ on $\mathrm{In}_{2} \mathrm{O}_{3}$ has an adsorption energy of $-1.25 \mathrm{eV}$, which is sufficiently exothermic and thus favorable, so the O-C-O angle of the $\mathrm{CO}_{2}$ on adsorbed on the $\mathrm{In}_{2} \mathrm{O}_{3}$ is significantly distorted relative to the gas phase structure, significantly increasing the activity of the $\mathrm{CO}_{2}$ in the RWGSR (Ye et al., 2012; Sun et al., 2014). The oxygen vacancies are increasingly created and stabilized on $\mathrm{In}_{2} \mathrm{O}_{3}$ with the presence of $\mathrm{CeO}_{2}$ in the $\mathrm{In}_{2} \mathrm{O}_{3}-\mathrm{CeO}_{2}$ catalyst, on which the dissociated $\mathrm{H}_{2}$ adsorption is enhanced and the amount of bicarbonate species resulting from activated $\mathrm{CO}_{2}$ is increased, which thus exhibits enhanced catalytic activity for the RWGSR (Wang et al., 2016c). Cubic $\mathrm{In}_{2} \mathrm{O}_{3}$ [denoted as $\mathrm{c}-\mathrm{In}_{2} \mathrm{O}_{3}(110)$ ] exhibits a higher RWGSR rate than the hexagonal $\mathrm{In}_{2} \mathrm{O}_{3}$ [denoted as h- $\left.\mathrm{In}_{2} \mathrm{O}_{3}(110)\right]$ at temperature below $350^{\circ} \mathrm{C}$ due to its enhanced dissociative adsorption of $\mathrm{H}_{2}$, facile formation of the oxygen vacancies, and enhanced ability to adsorb and activate $\mathrm{CO}_{2}$ on the oxygen vacancies (Wang et al., 2020). DFT calculations indicate that the oxygen vacancies sites on the $\mathrm{In}_{2} \mathrm{O}_{3}$ (110) surface assist $\mathrm{CO}_{2}$ activation and hydrogenation and stabilize the key intermediates involved in $\mathrm{CO}$ formation (Ye et al., 2013). Furthermore, an $\mathrm{In}_{2} \mathrm{O}_{3-\mathrm{x}}(\mathrm{OH})_{\mathrm{y}}$ surface containing both Lewis base hydroxide groups and Lewis acid In sites together with oxygen vacancies can heterolytically dissociate $\mathrm{H}_{2}$ to form a hydride bonded to In metal and a proton bonded to a lattice $\mathrm{O}$. This hydrogenated $\operatorname{In}_{2} \mathrm{O}_{3-\mathrm{x}}(\mathrm{OH})_{\mathrm{y}}$ surface facilitates $\mathrm{CO}_{2}$ reduction by mediating the charge transfer between the $\mathrm{In}_{2} \mathrm{O}_{3-\mathrm{x}}(\mathrm{OH})_{\mathrm{y}}$ surface and adsorbed reactants $\mathrm{CO}_{2}$ and $\mathrm{H}_{2}$ to form $\mathrm{CO}$ and $\mathrm{H}_{2} \mathrm{O}$ (Ghuman et al., 2015). Well-tempered MetaD-biased AIMD simulations have been performed, taking 


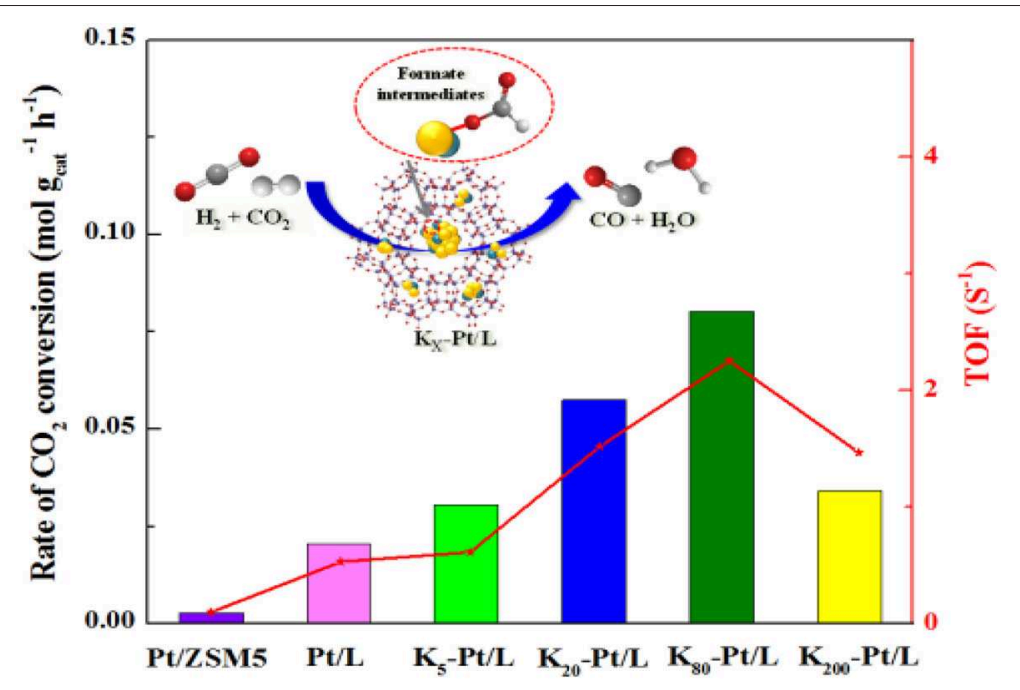

FIGURE 8 | RWGSR over Pt/L catalysts with different K contents. Reprinted with permission from Yang et al. (2017). Copyright (2017) Elsevier.

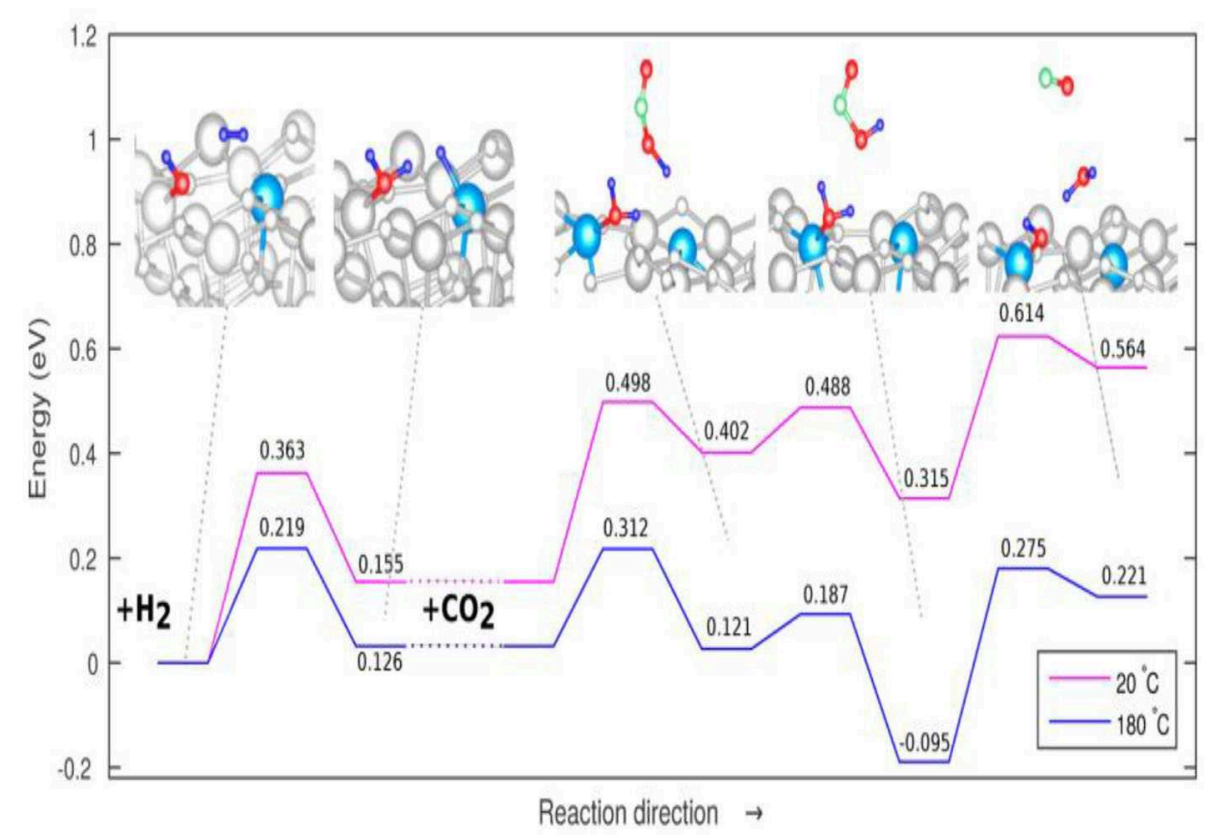

FIGURE 9 | Overall proposed mechanism for the RWGSR on $\ln _{2} \mathrm{O}_{3-x}(\mathrm{OH})_{y}$ at $20^{\circ} \mathrm{C}$ (pink line) and $180^{\circ} \mathrm{C}$ (blue line). Reprinted with permission from Ghoussoub et al. (2016). Copyright (2016) American Chemical Society.

the temperature into account, to probe the mechanism for the RGWS reaction over the $\operatorname{In}_{2} \mathrm{O}_{3-\mathrm{x}}(\mathrm{OH})_{\mathrm{y}}$ surface at temperatures of 20 and $180^{\circ} \mathrm{C}$, as shown in Figure 9, and the results show that the reduction of gaseous $\mathrm{CO}_{2}$ is the rate-limiting step, with no significant change resulting from increased temperature. However, the energy barrier corresponding to the adsorption of $\mathrm{CO}_{2}$ is slightly reduced at $180^{\circ} \mathrm{C}$ compared to the that at $20^{\circ} \mathrm{C}$, suggesting that the thermal effects may only be relevant to the reaction step characterized by an adsorptive mechanisms and that the increased thermal conditions may enhance the reactivity by enabling the surface frustrated Lewis pairs to become further spatially separated (Ghoussoub et al., 2016).

The perovskite-type oxides are represented by an $\mathrm{ABO}_{3}$ formula, where the A-site is typically occupied by lanthanides or alkaline earth metals, and the B-site is usually filled with transition metals (Yamazoe et al., 1981; Peña and Fierro, 2001; de Lima et al., 2009). With multiple cation combinations possible on each site, perovskite-type oxides can be easily customized to achieve desirable properties, such as high oxygen mobility and tunability, together with thermal stability at high temperatures 
without aggregation (Royer et al., 2005; Kae et al., 2014). Therefore, these materials are attractive for application to the RWGSR with chemical looping cycles (RWGSR-CL) that can convert $\mathrm{CO}_{2}$ and $\mathrm{H}_{2}$ to separate streams of $\mathrm{CO}$ and $\mathrm{H}_{2} \mathrm{O}$, as depicted in Figure 10 (Ringuedẽ and Fouletier, 2001). The combination of $\mathrm{La}$ and $\mathrm{Sr}$ in the A-site and metal in the Bsite enhances the formation of oxygen vacancies due to the generation of a charge imbalance in the $\mathrm{ABO}_{3}$ structure caused by the difference in their oxidation states (Daza et al., 2014). Regarding Co-based perovskite type oxides $\left(\mathrm{La}_{0.75} \mathrm{Sr}_{0.25} \mathrm{CoO}_{3-\delta}\right)$, under $\mathrm{H}_{2}$ flow conditions, their phases can change to metallic cobalt and base oxides $\left(\mathrm{Co} / \mathrm{SrCO}_{3} / \mathrm{La}_{2} \mathrm{O}_{3}\right)$, which are then reoxidized to a layered perovskite $\left(\mathrm{CoO} / \mathrm{LaSrCoO}_{4-\delta}\right)$ with a $\mathrm{K}_{2} \mathrm{NiF}_{4}$-type structure when exposed to $\mathrm{CO}_{2}$, thus producing $\mathrm{CO}$ during this cycle. Additionally, the optimal isothermal reduction and conversion temperatures for maximizing the $\mathrm{CO}$ product rates of $113.9 \mu \mathrm{mole} \mathrm{CO} / \mathrm{g} / \mathrm{min}$ are $500^{\circ} \mathrm{C}$ (of 400,500 , and $600^{\circ} \mathrm{C}$ ) and $850^{\circ} \mathrm{C}$ (of 650,750 , and $850^{\circ} \mathrm{C}$ ), presumably due to the formation of mixed oxides and metallic cobalt crystalline phases (observed via X-ray diffraction) in close contact under these conditions (Royer et al., 2005). Febased perovskite type oxides $\left[\mathrm{La}_{0.75} \mathrm{Sr}_{0.25} \mathrm{FeO}_{3}\right.$ (LSF)] have shown the greatest promise in the RWGSR-CL process due to the low energy barrier for oxidation-state transitions $\left(\mathrm{Fe}^{3+}-\mathrm{Fe}^{2+}\right)$ during the redox cycles (Peña and Fierro, 2001). Enhanced oxygen self-diffusion, material recyclability, and therefore the viability of LSF have been demonstrated for chemical looping when supported by redox materials with more abundant alternatives, such as $\mathrm{CeO}_{2}, \mathrm{ZrO}_{2}, \mathrm{Al}_{2} \mathrm{O}_{3}, \mathrm{SiO}_{2}$, and $\mathrm{TiO}_{2}$ (Li et al., 2011; Chen et al., 2014). In comparison, supports such as $\mathrm{TiO}_{2}$ and $\mathrm{Al}_{2} \mathrm{O}_{3}$ demonstrate SMSIs, which often result in some degree of LSF particle encapsulation, even at low temperatures, thus hindering the $\mathrm{CO}_{2}$ adsorption on the surface oxygen vacancies, whereas $\mathrm{SiO}_{2}$ demonstrates more moderate interactions that are strong enough and suitable for particle segregation yet weak enough to avoid deactivation (Min et al., 2003; Hare et al., 2019). These behaviors occur because the utilization of $\mathrm{SiO}_{2}$ as a support significantly reduces the average LSF crystallite size and the extent of oxygen selfdiffusion retardation, and the $\mathrm{CO}$ generation yields of $\mathrm{LSF} / \mathrm{SiO}_{2}$ surpass those of LSF alone by $\sim 200 \%$, producing $2.6 \mathrm{mmol}$ of $\mathrm{CO}_{\mathrm{gLSF}^{-1}}$ at a peak rate of $0.8 \mathrm{mmol} \mathrm{CO}_{\mathrm{gLSF}}{ }^{-1} \mathrm{~min}^{-1}$ (Hare et al., 2018). In addition, further modification of $\mathrm{Fe}$ based perovskite type oxides with transition metals helps to increase the strength of the interaction of the active species and support and thus stabilizes the unusual cationic oxidation state in the RWGSR process (Nitarori et al., 1988). The incorporation of $\mathrm{Cu}$ in $\mathrm{La}_{0.75} \mathrm{Sr}_{0.25} \mathrm{Fe}_{1-\mathrm{Y}} \mathrm{Cu}_{\mathrm{Y}} \mathrm{O}_{3}$ perovskites [Cu100*Y (with $\mathrm{Y}=0,0.10,0.25,0.50,0.75$, and 1)] facilitates the formation of oxygen vacancies at lower temperatures. $\mathrm{CO}$ production is promoted in the $\mathrm{Cu} 10$ sample vs. $\mathrm{Cu} 0$ and $\mathrm{Cu} 25$, likely due to a combined effect of better $\mathrm{CO}_{2}$ dissociative chemisorption energies on metallic $\mathrm{Cu}$ and decreased thermodynamic stability of the oxygen-deficient perovskites

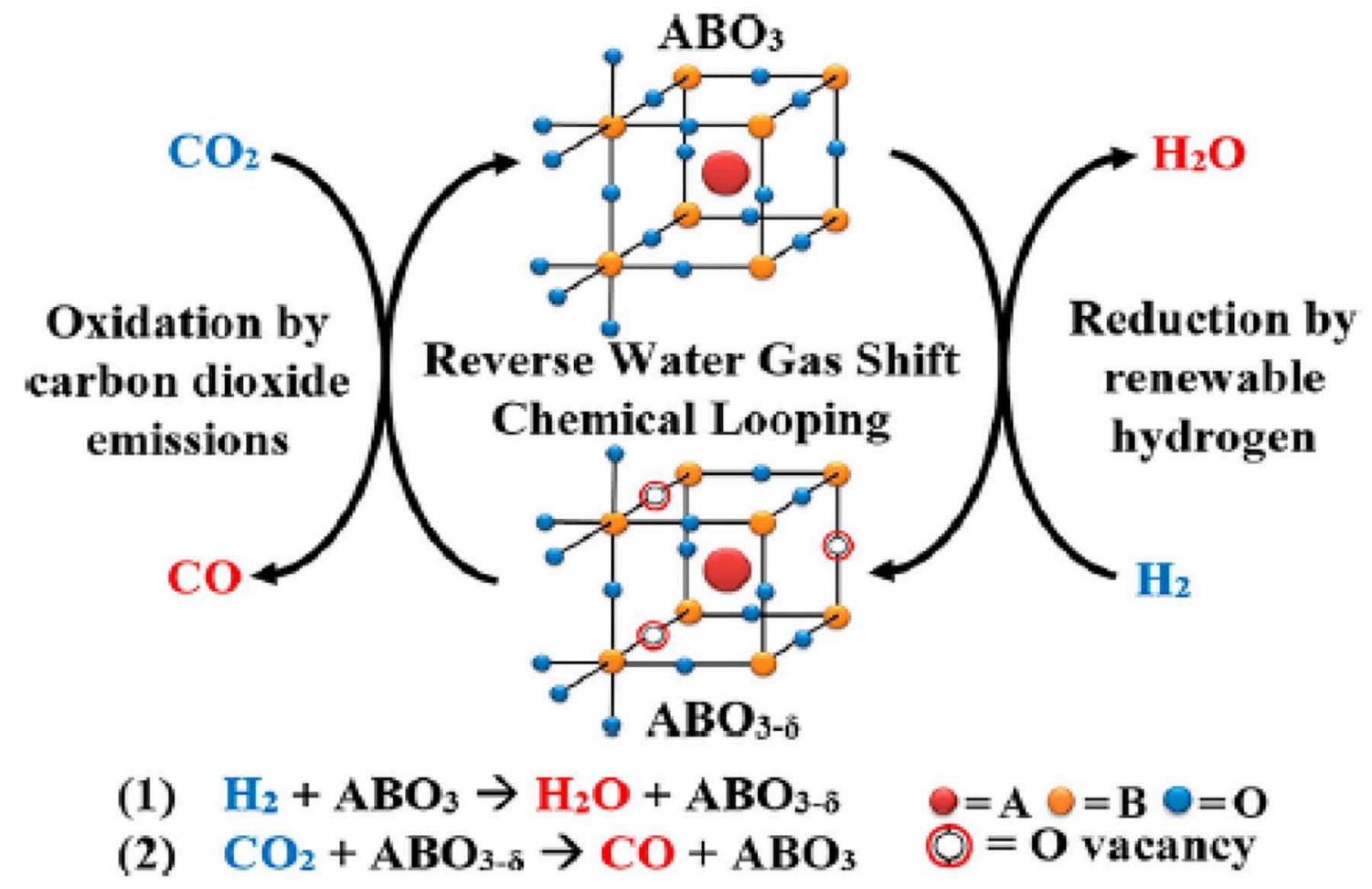

FIGURE 10 | Reverse water gas shift-chemical looping process. Reprinted with permission from Ringuedẽ and Fouletier (2001). Copyright (2018) American Chemical Society. 
(Daza et al., 2016). The enhanced crystalline structure stability is aroused by the incorporation of $\mathrm{Co}$ in the $\mathrm{La}_{0.75} \mathrm{Sr}_{0.25} \mathrm{Co}_{(1-\mathrm{Y})}$ $\mathrm{Fe}_{\mathrm{Y}} \mathrm{O}_{3}$ perovskite. Additionally, a computational investigation using DFT calculations correlates $\mathrm{CO}_{2}$ adsorption strength, generally a strong barrier in $\mathrm{CO}_{2}$ conversion, on the (100) crystal facets on $\mathrm{La}_{0.75} \mathrm{Sr}_{0.25} \mathrm{FeO}_{(3-\delta)}$ to increasing the surface oxygen vacancies $(\delta)$. Therefore, $\delta$ in the perovskite is the driving force to break the CO-O bond and reoxidize the $\mathrm{La}_{0.75} \mathrm{Sr}_{0.25} \mathrm{FeO}_{3-\delta}$ (Daza et al., 2015; Maiti et al., 2016).

\section{CONCLUSION AND OUTLOOK}

The large-scale conversion of $\mathrm{CO}_{2}$ to $\mathrm{CO}$ via the RWGSR is a promising route with great potential for use in the near future, provided a mature technology for commercial production of renewable $\mathrm{H}_{2}$ is also available. The RWGSR also achieves higher $\mathrm{CO}_{2}$ conversion than other relevant technologies that meet the global $\mathrm{CO}_{2}$ emissions standards. Because it is a slightly endothermic and pressure-independent reaction, the current challenge for RWGSR employed in fuel synthesis is the design of thermally stable materials that can achieve high $\mathrm{CO}$ selectivity and high production rates. Preferential strategies have recently been enacted to address the existing problems either by modulating the SMSI, size of the active metal, second metal composition, and addition of alkali promoter for supported catalysts or by dipping with additional heteroatoms or tuning their crystal planes for oxide catalysts. Furthermore, the perovskitetype oxides can act as the oxygen donor-acceptor for the RWGSR-CL to not only circumvent thermodynamic and kinetic limitations but also eliminate the possibility of methanation as a side reaction because there is no direct interaction between two feed gases and between two product streams.

From this systematic introduction, the relationships between the nature of the active sites and the main intermediates of RWGSR catalysts are understood through the insights gained

\section{REFERENCES}

Ahn, K. Y., Yoo, D. S., Prasad, D. H., Lee, H. W., Chung, Y. C., and Lee, J. H. (2012). Role of multivalent $\mathrm{Pr}$ in the formation and migration of oxygen vacancy in $\mathrm{Pr}-$ Doped ceria: experimental and first-principles investigations. Chem. Mater. 24, 4261-4267. doi: $10.1021 / \mathrm{cm} 3022424$

Álvarez Galván, C., Schumann, J., Behrens, M., Fieero, J. L. G., Schlogl, R., and Frei, E. (2016). Reverse water-gas shift reaction at the $\mathrm{Cu} / \mathrm{ZnO}$ interface: influence of the $\mathrm{Cu} / \mathrm{Zn}$ ratio on structure-activity correlations. Appl. Catal. B-Environ. 195, 104-111. doi: 10.1016/j.apcatb.2016.05.007

Aresta, M., Dibenedetto, A., and Angelini, A. (2014). Catalysis for the valorization of exhaust carbon: from $\mathrm{CO}_{2}$ to chemicals, materials, and fuels technological use of $\mathrm{CO}_{2}$. Chem. Rev. 114, 1709-1742. doi: 10.1021/cr40 02758

Aresta, M., Dibenedetto, A., and Quaranta, E. (2016). State of the art and perspectives in catalytic processes for $\mathrm{CO}_{2}$ conversion into chemicals and fuels: the distinctive contribution of chemical catalysis and biotechnology. J. Catal. 343, 2-45. doi: 10.1016/j.jcat.2016.04.003

Arunajatesan, V., Subramaniam, B., Hutchenson, K. W., and Herkes, F. E. (2001). Fixed-bed hydrogenation of organic compounds in supercritical from the molecular dynamic simulations and mechanistic work under the operando reaction conditions, which is beneficial to the development of state-of-the-art architecture of RWGSR catalysts. However, even though several materials have been studied, improvements are still possible, especially for commercial development of RWGSR catalysts for laboratory and market applications. If the RWGSR plays a major role in the reduction of the atmospheric $\mathrm{CO}_{2}$ concentration, then designing catalysts with earth-abundant materials will be necessary and desirable. To develop supported metals, both Fe oxides and Ni oxides are chosen to be investigated as representative substitutes for the most commonly used reducible supports, such as $\mathrm{CeO}_{2}, \mathrm{ZnO}$, and $\mathrm{In}_{2} \mathrm{O}_{3}$, largely due to their oxygen vacancies with high oxygen mobility and stability, which can activate $\mathrm{CO}_{2}$ more easily by accommodating oxygen due to the $\mathrm{C}-\mathrm{O}$ bond cleavage in the RWGSR. Additionally, transition metal carbides are attractive and convenient alternatives for industrial use in the RWGSR because of their properties, which are similar to those of precious metals, as well as their dual functionality for $\mathrm{H}_{2}$ dissociation and $\mathrm{C}-\mathrm{O}$ bond scission and their potential to behave similarly to reducible oxides.

\section{AUTHOR CONTRIBUTIONS}

$\mathrm{XC}, \mathrm{CS}$, and YC drafted the manuscript, conceived the concept of the review, conducted literature survey, and arranged the figures. NW provided the suggestions. WW and LC revised the manuscript and provided comments. All authors contributed to the article and approved the submitted version.

\section{FUNDING}

This project is financially supported by the Startup Research Fund of Dongguan University of Technology (KCYKYQD2017015), the Postdoctoral Startup Research Fund of Dongguan University of Technology (No.196100040019), and the China Postdoctoral Science Foundation (No. 2019M653608). carbon dioxide. Chem. Eng. Sci. 56, 1363-1369. doi: 10.1016/S0009-2509(00)0 0359-6

Arunajatesan, V., Subramaniam, B., Hutchenson, K. W., and Herkes, F. E. (2007). In situ FTIR investigations of reverse water gas shift reaction activity at supercritical conditions. Chem. Eng. Sci. 62, 5062-5069. doi: 10.1016/j.ces.2007.01.010

Avanesian, T., Gusmão, G. S., and Christopher, P. (2016). Mechanism of $\mathrm{CO}_{2}$ reduction by $\mathrm{H}_{2}$ on $\mathrm{Ru}(0001)$ and general selectivity descriptors for latetransition metal catalysts. J. Catal. 343, 86-96. doi: 10.1016/j.jcat.2016.03.016

Bahmanpour, A. M., Héroguel, F., Kiliç M., Baranowski, C. J., Artiglia, L., Rothlisberger, U., et al. (2019). Cu-Al spinel as a highly active and stable catalyst for the reverse water gas shift reaction. ACS Catal. 9, 6243-6251. doi: 10.1021/acscatal.9b01822

Bahmanpour, A. M., Héroguel, F., Kiliç M., Baranowski, C. J., Schouwink, P., and Röthlisberger, U. (2020). Essential role of oxygen vacancies of $\mathrm{Cu}-\mathrm{Al}$ and $\mathrm{Co}-\mathrm{Al}$ spinel oxides in their activity for the reverse water gas shift reaction. Appl. Catal. B-Environ. 266:118669. doi: 10.1016/j.apcatb.2020.1 18669

Barnard, C. F. J. (2008). Palladium-catalyzed carbonylation -a reaction come of age. Organometallics 27, 5402-5422. doi: 10.1021/om800549q 
Batista, A. H. M., Ramos, F. S. O., Braga, T. P., Lima, C. L., de Sousa, F. F., de Barros, E. B., et al. (2010). Mesoporous $\mathrm{MAl}_{2} \mathrm{O}_{4}(\mathrm{M}=\mathrm{Cu}, \mathrm{Ni}, \mathrm{Fe}$ or $\mathrm{Mg}$ ) spinels: characterisation and application in the catalytic dehydrogenation of ethylbenzene in the presence of $\mathrm{CO}_{2}$. Appl. Catal. A-Gen. 382, 148-157. doi: 10.1016/j.apcata.2010.04.027

Bobadilla, L. F., Santos, J. L., Ivanova, S., Odriozola, J. A., and Urakawa, A. (2018). Unravelling the role of oxygen vacancies in the mechanism of the reverse watergas shift reaction by operando drifts and ultraviolet-visible spectroscopy. ACS Catal. 8, 7455-7467. doi: 10.1021/acscatal.8b02121

Bogolowski, N., Batalla, B. S., Shin, B., and Drillet, J. F. (2020). Activity of $\mathrm{La}_{0.75} \mathrm{Sr}_{0.25} \mathrm{Cr}_{0.5} \mathrm{Mn}_{0.5} \mathrm{O}_{3-\delta}, \mathrm{Ni}_{3} \mathrm{Sn}_{2}$ and $\mathrm{Gd}$-doped $\mathrm{CeO}_{2}$ towards the reverse water-gas shift reaction and carburisation for a high temperature $\mathrm{H}_{2} \mathrm{O} / \mathrm{CO}_{2}$ co-electrolysis. RSC Adv. 10, 10285-10296. doi: 10.1039/D0RA00362J

Brennführer, A., Neuman, H., and Beller, M. (2009). Palladium-catalyzed carbonylation reactions of aryl halides and related compounds. Angew. Chem. Int. Ed. 48, 4114-4133. doi: 10.1002/anie.200900013

Burri, D. R., Choi, K. M., Han, S. C., Burri, A., and Park, S. E. (2007). Selective conversion of ethylbenzene into styrene over $\mathrm{K}_{2} \mathrm{O} / \mathrm{TiO}_{2}-\mathrm{ZrO}_{2}$ catalysts: unified effects of $\mathrm{K}_{2} \mathrm{O}$ and $\mathrm{CO}_{2}$. J. Mol. Catal. A-Chem. 269, 58-63. doi: 10.1016/j.molcata.2006.12.021

Cadi-Essadek, A., Roldan, A., Aparicio-Anglès, X., and de Leeuw, N. H. (2018). $\mathrm{CO}_{2}$ and $\mathrm{H}_{2}$ adsorption and reaction at $\mathrm{Ni}_{n} / \mathrm{YSZ}(111)$ interfaces: a density functional theory study. J. Phys. Chem. C 122, 19463-19472. doi: 10.1021/acs.jpcc.8b03488

Cao, Z., Guo, L., Liu, N. Y., Zheng, X. L., Li, W. L., Shi, Y. Y., et al. (2016). Theoretical study on the reaction mechanism of reverse watergas shift reaction using a $\mathrm{Rh}-\mathrm{Mo}_{6} \mathrm{~S}_{8}$ cluster. RSC Adv. 6, 108270-108279. doi: 10.1039/C6RA23855F

Carrasquillo-Flores, R., Ro, I., Kumbhalkar, M. D., Burt, S., Carrero, C. A., AlbaRubio, A. C., et al. (2015). Reverse water-gas shift on interfacial sites formed by deposition of oxidized molybdenum moieties onto gold nanoparticles. J. Am. Chem. Soc. 137, 10317-10325. doi: 10.1021/jacs.5b05945

Centi, G., and Perathoner, S. (2009). Opportunities and prospects in the chemical recycling of carbon dioxide to fuels. Catal. Today 148, 191-205. doi: 10.1016/j.cattod.2009.07.075

Chen, C. S., and Cheng, W. H. (2002). Study on the mechanism of CO formation in reverse water gas shift reaction over $\mathrm{Cu} / \mathrm{SiO}_{2}$ catalyst by pulse reaction, TPD and TPR. Catal. Lett. 83, 121-126. doi: 10.1023/A:1021006718974

Chen, C. S., Cheng, W. H., and Lin, S. S. (2000). Mechanism of CO formation in reverse water-gas shift reaction over $\mathrm{Cu} / \mathrm{Al}_{2} \mathrm{O}_{3}$ catalyst. Catal. Lett. 68, 45-48. doi: 10.1023/A:1019071117449

Chen, C. S., Cheng, W. H., and Lin, S. S. (2003). Study of reverse water gas shift reaction by TPD, TPR and $\mathrm{CO}_{2}$ hydrogenation over potassium-promoted $\mathrm{Cu} / \mathrm{SiO}_{2}$ catalyst. Appl. Catal. A-Gen. 238, 55-67. doi: 10.1016/S0926-860X(02)00221-1

Chen, C. S., Cheng, W. H., and Lin, S. S. (2004). Study of iron-promoted $\mathrm{Cu} / \mathrm{SiO}_{2}$ catalyst on high temperature reverse water gas shift reaction. Appl. Catal. A Gen. 257, 97-106. doi: 10.1016/S0926-860X(03)0 0637-9

Chen, X. D., Su, X., Duan, H. M., Liang, B. L., Huang, Y. Q., and Zhang, T. (2017a). Catalytic performance of the $\mathrm{Pt} / \mathrm{TiO}_{2}$ catalysts in reverse water gas shift reaction: Controlled product selectivity and a mechanism study. Catal. Today 281, 312-318. doi: 10.1016/j.cattod.201 6.03 .020

Chen, X. D., Su, X., Liang, B. L., Yang, X. L., Ren, X. Y., Duan, H. M., et al. (2016). Identification of relevant active sites and a mechanism study for reverse water gas shift reaction over $\mathrm{Pt} / \mathrm{CeO}_{2}$ catalysts. J. Energy Chem. 25, 1051-1057. doi: 10.1016/j.jechem.2016.11.011

Chen, X. D., Su, X. H., Su, Y., Liu, X. Y., Miao, S., Zhao, Y. H., et al. (2017b). Theoretical insights and the corresponding construction of supported metal catalysts for highly selective $\mathrm{CO}_{2}$ to $\mathrm{CO}$ conversion. ACS Catal. 7, 4613-4620. doi: 10.1021/acscatal.7b00903

Chen, Y., Galinsky, N., Wang, Z., and Li, F. (2014). Investigation of perovskite supported composite oxide oxides for chemical looping conversion of syngas. Fuel 134, 521-530. doi: 10.1016/j.fuel.2014.06.017

Choi, P. H., Jun, W. K., Lee, J. S., Choi, J. M., and Lee, W. K. (1996). Hydrogenation of carbon dioxide over alumina supported Fe-K catalysts. Catal. Lett. 40 115-118. doi: 10.1007/BF00807467
Connor, C. P., and Holland, P. L. (2017). Coordination chemistry insights into the role of alkali metal promoters in dinitrogen reduction. Catal. Today 286 21-40. doi: 10.1016/j.cattod.2016.08.014

Cosultchi, A., Pérez-Luna, M., Morales-Serna, J. A., and Salmón, M. (2012). Characterization of modified Fischer-Tropsch catalysts promoted with alkaline metals for higher alcohol synthesis. Catal. Lett. 142, 368-377. doi: 10.1007/s10562-012-0765-9

Dai, B., Cao, S. Q., Xie, H. M., Zhou, G. L., and Chen, S. M. (2018). Reduction of $\mathrm{CO}_{2}$ to $\mathrm{CO}$ via reverse water-gas shift reaction over $\mathrm{CeO}_{2}$ catalyst. Korean J. Chem. Eng. 35, 421-427. doi: 10.1007/s11814-017-0267-y

Daza, Y. A., Kent, R. A., Yung, M. M., and Kuhn, J. N. (2014). Carbon dioxide conversion by reverse water- gas shift chemical looping on perovskite-type oxides. Int. Eng. Chem. Res. 53, 5828-5837. doi: 10.1021/ie5002185

Daza, Y. A., Maiti, D., Hare, B. J., Bhethanabotla, V. R., Kuhn, J. N., and More, CU, (2016). More problems: decreased $\mathrm{CO}_{2}$ conversion ability by $\mathrm{Cu}$-doped $\mathrm{La}_{0.75} \mathrm{Sr}_{0.25} \mathrm{FeO}_{3}$ perovskite oxides. Surf. Sci. 648, 92-99. doi: 10.1016/j.susc.2015.11.017

Daza, Y. A., Maiti, D., Kent, R. A., Bhethanabotla, V. R., and Kuhn, J. N. (2015). Isothermal reverse water gas shift chemical looping on $\mathrm{La}_{0.75} \mathrm{Sr}_{0.25} \mathrm{Co}_{1-\mathrm{Y}} \mathrm{Fe}_{\mathrm{Y}} \mathrm{O}_{3}$ perovskite-type oxides. Catal. Today 258, 691-698. doi: $10.1016 /$ j.cattod.2014.12.037

de Lima, R. K. C., Batista, M. S., Wallau, M., Sanches, E. A., Mascarenhas, Y. P., and Urquieta-González, E. A. (2009). High specific surface area LaFeCo perovskite synthesis by nanocasting and catalytic behavior in the reduction of NO with CO. Appl. Catal. B-Environ. 9, 441-450. doi: 10.1016/j.apcatb.2009.04.004

Delgado, J. J., José, M. C., López-Haro, M., del, R. E., Calvino, J. J., Serafín B, et al. (2011). Recent process in chemical characterization of supported gold catalysts: CO adsorption on Au/ceira-zirconia. Chem. Lett. 40, 1210-1216. doi: $10.1246 / \mathrm{cl} .2011 .1210$

Diebold, U. (2003). The surface science of titanium dioxide. Sur. Sci. Rep. 48, 53-229. doi: 10.1016/S0167-5729(02)00100-0

Dong, Q., Yin, S., Guo, C. S., and Sato, T. (2012). $\mathrm{Ce}_{0.5} \mathrm{Zr}_{0.4} \mathrm{Sn}_{0.1} \mathrm{O}_{2} / \mathrm{Al}_{2} \mathrm{O}_{3}$ catalysts with enhanced oxygen storage capacity and high $\mathrm{CO}$ oxidation activity. Catal. Sci. Technol. 2, 2521-2524. doi: 10.1039/c2cy20425h

Feyzi, M., Irandoust, M., and Mirzaei, A. A. (2011). Effects of promoters and calcination conditions on the catalytic performance of iron-manganese catalysts for fisher-tropsch synthesis. Fuel Process. Technol. 92, 1136-1143. doi: 10.1016/j.fuproc.2011.01.010

Fornero, E. L., Chiavassa, D. L., Bonivardi, A. L., and Baltanás, M. A. (2017). Transient analysis of the reverse water gas shift reaction on $\mathrm{Cu} / \mathrm{ZrO}_{2}$ and $\mathrm{Ga}_{2} \mathrm{O}_{3} / \mathrm{Cu} / \mathrm{ZrO}_{2}$ catalysts. J. CO2 Util. 22, 289-298. doi: $10.1016 /$ j.jcou.2017.06.002

Fu, Q., and Wagner, T. (2007). Interaction of nanostructured metal overlayers with oxide surfaces. Sur. Sci. Rep. 62, 431-498. doi: 10.1016/j.surfrep.2007.07.001

Fujita, S. L., Usui, M., and Takezawa, N. (1992). Mechanism of the reverse water gas shift reaction over $\mathrm{Cu} / \mathrm{ZnO}$ catalyst. J. Catal. 134, 220-225. doi: 10.1016/0021-9517(92)90223-5

Gálvez, M. E., Ascaso, S., and Moliner, R., Lázaro MJ (2013). Influence of the alkali promoter on the activity and stability of transition metal $(\mathrm{Cu}, \mathrm{Co}, \mathrm{Fe})$ based structured catalysts for the simutaneous removal of soot and $\mathrm{NO}_{\mathrm{x}}$. Top Catal. 56, 493-498. doi: 10.1007/s11244-013-0004-7

Gao, S., Lin, Y., Jiao, X. C., Sun, Y. F., Luo, Q. Q., Zhang, W. H., et al. (2016). Partially oxidized atomic cobalt layers for carbon dioxide electroreduction to liquid fuel. Nature 529, 68-71. doi: 10.1038/nature16455

Garin, F. (2001). Mechanism of $\mathrm{NO}_{\mathrm{x}}$ decompositon. Appl. Catal. A- Gen. 222, 183-219. doi: 10.1016/S0926-860X(01)00827-4

Ghoussoub, M., Yadav, S., Ghuman, K. K., Ozin, G. A., and Singh, C. V. (2016). Metadynamics-biased ab initio molecular dynamics study of heterogeneous $\mathrm{CO}_{2}$ reduction via surface frustrated lewis pairs. ACS Catal. 6, 7109-7117. doi: 10.1021/acscatal.6b01545

Ghuman, K. K., Wood, T. E., Hoch, L. B., Mims, C. A., Ozin, G. A., and Singh, C. V. (2015). Illuminating $\mathrm{CO}_{2}$ reduction on frustrated lewis pair surfaces: investigating the role of surface hydroxides and oxygen vacancies on nanocrystalline $\operatorname{In}_{2} \mathrm{O}_{3-\mathrm{x}}(\mathrm{OH})_{\mathrm{y}}$. Phys. Chem. Chem. Phys. 17, 14623-14635. doi: 10.1039/C5CP02613J

Gines, M. J. L., March, A. J., and Apesteguia, C. R. (1997). Kinetic study of the reverse water-gas shift reaction over $\mathrm{CuO} / \mathrm{ZnO} / \mathrm{Al}_{2} \mathrm{O}_{3}$ catalysts. Appl. Catal. A-Gen. 154, 155-171. doi: 10.1016/S0926-860X(96)00369-9 
Goguet, A., Meunier, F., Breen, J. P., Burch, R., Petch, M. I., and Ghenciu, A. F. (2004b). Study of the origin of the deactivation of a $\mathrm{Pt} / \mathrm{CeO}_{2}$ catalyst during reverse water gas shift (RWGSR) reaction. J. Catal. 226, 382-392. doi: 10.1016/j.jcat.2004.06.011

Goguet, A., Meunier, F. C., Tibiletti, D., Breen, J. P., and Burch, T. (2004a). Spectrokinetic investigation of reverse water-gas-shift reaction intermediates over a Pt/CeO 2 catalyst. J. Phys. Chem. B 108, 20240-20246. doi: $10.1021 / j p 047242 \mathrm{w}$

Goguet, A., Shekhtman, S. O., Burch, R., Hardacre, C., Meunier, F. C., and Yablonsky, G. S. (2016). Pulse-response TAP studies of the reverse water-gas shift reaction over a $\mathrm{Pt} / \mathrm{CeO}_{2}$ catalyst. J. Catal. 237, 102-110. doi: 10.1016/j.jcat.2005.10.020

Graciani, J., Mudiyanselage, K., Xu, F., Baber, A. E., Evans, J., Senanayake, S. D., et al. (2014). Highly active copper-ceria and copper-ceira-titania catalysts for methanol synthesis from $\mathrm{CO}_{2}$. Science 345 546-550. doi: 10.1126/science.1253057

Han, Y. Q., Xu, H. T., Su, Y. Q., Xu, Z. L., Wang, K. F., and Wang, W. Z. (2019). Noble metal (Pt, Au@Pd) nanoparticles supported on metal organic framework (MOF-74) nanoshuttles as high-selectivity $\mathrm{CO}_{2}$ conversion catalysts. J. Catal. 370, 70-78. doi: 10.1016/j.jcat.2018.12.005

Hare, B. J., Maiti, D., Daza, Y. A., Bhethanabotla, V. R., and Kuhn, J. N. (2018). Enhanced $\mathrm{CO}_{2}$ conversion to $\mathrm{CO}$ by silica-supported perovskite oxide at low temperatures. ACS Catal. 8, 3021-3029. doi: 10.1021/acscatal.7b03941

Hare, B. J., Maiti, D., Ramani, S., Ramos, A. E., and Bhethanabotla, V. R. (2019). Thermochemical conversion of carbon dioxide by reverse water-gas shift chemical looping using supported pervoskite oxides. Catal. Today 323, 225-232. doi: 10.1016/j.cattod.2018.06.002

He, Y. L., Yang, K. R., Yu, Z. W., Fishman, Z. S., Achola, L. A., and Tobin, Z. M. (2019). Catalytic manganese oxide nanostructures for the reverse water gas shift reaction. Nanoscale 11, 16677-16688. doi: 10.1039/C9NR06078B

Huš M., Dasireddy, V. D. B. C., Stefancic, N. S., and Likozar, B. (2017). Mechanism, kinetics and thermodynamics of carbon dioxide hydrogenation to methanol on $\mathrm{Cu} / \mathrm{ZnAl}_{2} \mathrm{O}_{4}$ spinel-type heterogeneous catalysts. Appl. Catal. B-Environ. 207, 267-278. doi: 10.1016/j.apcatb.2017.01.077

Ishito, N., Hara, K. J., Nakajima, K., and Fukuoka, A. (2016). Selective synthesis of carbon monoxide via formates in reverse water-gas shift reaction over alumina-supported gold catalyst. J. Energy Chem. 25, 306-310. doi: 10.1016/j.jechem.2015.12.005

Jafari, A., Ebadi, A., and Sahedbedlfar, S. (2019). Effect of iron oxide precursor on the properties and ammonia synthesis activity of fused iron catalysts. React. Kinet. Mech. Cat. 126, 307-325. doi: 10.1007/s11144-018-1498-6

Jing, H. J., Li, Q. H., Wu, J., Liu, D. W., and Wu, K. C. (2019). Theoretical study of the reverse water gas shift reaction on copper modified $\beta-\mathrm{Mo}_{2} \mathrm{C}(001)$ surfaces. J. Phys. Chem. C 123, 1235-1251. doi: 10.1021/acs.jpcc.8b09884

Jones, J. H. (2000). Te cativa process for the manufacture of acetic acid. Iridium catalyst improves productivity in an established industrial process. Platin. Met. Rev. 44, 94-105.

Joo, O. S., and Jung, K. D. (2003). Stability of $\mathrm{ZnAl}_{2} \mathrm{O}_{4}$ catalyst for reverse-water-gas-shift reaction (RWGSR). B Korean Chem. Soc. 24:1. doi: 10.5012/bkcs.2003.24.1.086

Kae, H. K., Park, J. L., Park, E. J., Dim, Y. D., and SUhm, H. (2014). Dopant effect of barium zirconate-based perovskite-type catalysts for the intermediatetemperature reverse water gas shift reaction. ACS Catal. 4, 3117-3122. doi: $10.1021 / \operatorname{cs} 500476 \mathrm{e}$

Kang, J., Czaja, A. D., and Guliants, V. V. (2017). Carbon dioxide as feedstock in selective oxidation of propane. Eur. J. Inorg. Chem. 2017, 4757-4762. doi: 10.1002/ejic.201701049

Karelovic, A., Galdames, G., Median, J. C., Yévenes, C., Barra, Y., and Jiménez, R. (2019). Mechanism and structure sensitivity of methanol synthesis from $\mathrm{CO}_{2}$ over $\mathrm{SiO}_{2}$-supported $\mathrm{Cu}$ nanoparticles. J. Catal. 369, 419-426. doi: $10.1016 /$ j.jcat.2018.11.012

Katta, L., Sudarsamam, P., Thrimurthulu, G., and Reddy, B. M. (2010). Doped nanosized ceria solid solutions for low temperature soot oxidation: zirconium versus lanthanum promoters. Appl. Catal. B-Environ. 101, 101-108. doi: 10.1016/j.apcatb.2010.09.012

Kattel, S., Liu, P., and Chen, J. G. (2017). Tuning selectivity of RWGSR reactions at the metal/oxide interface. J. Am. Chem. Soc. 139, 9739-9754. doi: $10.1021 /$ jacs.7b05362
Kattel, S., Yan, B. H., Chen, J. G. G., and Liu, P. (2016a). RWGSR on Pt, Pt/SiO 2 and $\mathrm{Pt} / \mathrm{TiO}_{2}$ : importance of synergy between $\mathrm{Pt}$ and oxide support. J. Catal. 343, 115-126. doi: 10.1016/j.jcat.2015.12.019

Kattel, S., Yu, W. T., Yang, X. F., Yan, B. H., Huang, Y. Q., Wan, W. M., et al. (2016b). $\mathrm{CO}_{2}$ hydrogenation over oxide-supported PtCo catalysts the role of the oxide support in determining the product selectivity. Angew. Chem. Int. Ed. 55, 7968-7973. doi: 10.1002/anie.201601661

Kharaji, A. G., Shariati, A., and Ostadi, M. (2014). Development of Ni-Mo/ $/ \mathrm{Al}_{2} \mathrm{O}_{3}$ catalyst for reverse water gas shift (RWGSR) reaction. J. Nanosci. Nanotechno. 14, 6841-6847. doi: 10.1166/jnn.2014.8962

Kharaji, A. G., Shariati, A., and Takassi, M. A. (2013). A novel $\gamma$-alumina supported Fe-Mo bimetallic catalyst for reverse water gas shift reaction. Chinese J. Chem. Eng. 21, 1007-1014. doi: 10.1016/S1004-9541(13)60573-X

Kim, D. H., Han, S. W., Yoon, H. S., and Kim, Y. D. (2015). Reverse water gas shift reaction catalyzed by $\mathrm{Fe}$ nanoparticles with high catalytic activity and stability. J. Ind. Eng. Chem. 23, 67-71. doi: 10.1016/j.jiec.2014.07.043

Kim, S. S., Lee, H. H., and Hong, S. C. (2012a). The effect of the morphological characteristics of $\mathrm{TiO}_{2}$ supports on the reverse water-gas shift reaction over $\mathrm{Pt} / \mathrm{TiO}_{2}$ catalysts. Appl. Catal. B-Environ. 119-120, 100-108. doi: 10.1016/j.apcatb.2012.02.023

Kim, S. S., Lee, H. H., and Hong, S. C. (2012b). A study on the effect of support's reducibility on the reverse water-gas shift reaction over Pt catalysts. Appl. Catal. A-Gen. 423-424, 100-107. doi: 10.1016/j.apcata.2012.02.021

Kim, S. S., Park, K. H., and Hong, S. C. (2013). A study of the selectivity of the reverse water-gas-shift reaction over $\mathrm{Pt} / \mathrm{TiO} 2$ catalysts. Fuel Process. Technol. 108 47-54. doi: 10.1016/j.fuproc.2012.04.003

Klankermayer, J., Wesselbaum, S., Beydoun, K., and Leitner, W. (2016). Selective catalytic synthesis using the combination of carbon dioxide and hydrogen: catalytic chess at the interface of energy and chemistry. Angew. Chem. Int. Ed. 55, 7296-7343. doi: 10.1002/anie.201507458

Klvana, D., Kirchnerová J., and Tofan, C. (1999). Catalytic decomposition of nitric oxide by perovskites. Korean J. Chem. Eng. 16, 470-477. doi: $10.1007 / \mathrm{BF} 02698270$

Kovacevic, M., Mojet, B. L., van Ommen, J. G., and Lefferts, L. (2016). Effects of morphology of cerium oxide catalysts for reverse water gas shift reaction. Catal. Lett. 146, 770-777. doi: 10.1007/s10562-016-1697-6

Krstajić, V. N., Lačnjevac, C. M., Jakšić J. M., and Jakšić M. M. (2008). Interactive supported electrocatalysts and spillover effect in electrocatalysis for hydrogen and oxygen electrode reactions. Chem. Ind. Chem. Q. 14, 119-136. doi: 10.2298/CICEQ0802119J

Kwak, J. H., Kovarik, L., and Szanyi, J. (2013a). Heterogeneous catalysis on atomically dispersed supported metals: $\mathrm{CO}_{2}$ reduction on multifunctional $\mathrm{Pd}$ catalysts. ACS Catal. 3, 2094-2100. doi: 10.1021/cs4001392

Kwak, J. H., Kovarik, L., and Szanyi, J. (2013b). $\mathrm{CO}_{2}$ reduction on supported $\mathrm{Ru} / \mathrm{Al}_{2} \mathrm{O}_{3}$ catalysts: cluster size dependence of product selectivity. ACS Catal. 3, 2449-2455. doi: 10.1021/cs400381f

Li, D., Ichikuni, N., Shimazu, S., and Uematsu, T. (1998). Catalytic properties of sprayed $\mathrm{Ru} / \mathrm{Al}_{2} \mathrm{O}_{3}$ and promoter effects of alkali metals in RWGSR. Appl. Catal. A-Gen. 172, 351-358. doi: 10.1016/S0926-860X(98)00139-2

Li, F., Luo, S., Sun, Z., Bao, X., and Fan, L. (2011). Role of metal oxide support in redox reactions of iron oxide for chemical looping applications; experiments and density functional theory calculations. Energy Environ. Sci. 4, 3661-3667. doi: 10.1039/clee01325d

Li, L., Hu, L. P., Li, J., and Wei, Z. D. (2015). Enhanced stability of Pt nanoparticle electrocatalysts for fuel cells. Nano Res. 8, 418-440. doi: 10.1007/s12274-014-0695-5

Li, R. X., Yabe, S., Yamashita, M., Momose, S., Yoshida, S., Yin, S., et al. (2002). UV-shielding properties of zinc oxide-doped ceria fine powders derived via soft solution chemical routes. Mater. Chem. Phys. 75, 39-44. doi: 10.1016/S0254-0584(02)00027-5

Li, S. W., Xu, Y., Chen, Y. F., Li, W. Z., Lin, L. L., Li, M. Z., et al. (2017), Tuning the selectivity of catalytic carbon dioxide hydrogenation over iridium/cerium oxide catalysts with a strong metal-support interaction. Angew. Chem. Int. Ed. 56, 10761-10765. doi: 10.1002/anie.201705002

Liang, B., Duan, H. M., Su, X., Chen, X. D., Huang, Y. Q., Chen, X. W., et al. (2017). Promoting role of potassium in the reverse water gas shift reaction on $\mathrm{Pt} /$ mullite catalyst. Catal. Today 281, 319-326. doi: $10.1016 /$ j.cattod.2016.02.051 
Lin, B., Liu, Y., Heng, L., Ni, J., Lin, J. X., and Jiang, L. L. (2018a). Effect of barium and potassium promoter on $\mathrm{Co} / \mathrm{CeO}_{2}$ catalysts in ammonia synthesis. J. Rare Earth. 36, 703-707. doi: 10.1016/j.jre.2018.01.017

Lin, F. J., Delmelle, R., Vinodkumar, T., Reddy, B. M., Wokaun, A., and Alxneit, I. (2015). Correlation between the structural characteristics, oxygen storage capacities and catalystic activities of dual-phase $\mathrm{Zn}$-modified ceria nanocrystals. Catal. Sci. Technol. 5, 3556-3567. doi: 10.1039/C5CY00351B

Lin, L. L., Yao, S. Y., Liu, Z. Y., Zhang, F., Li, N., Vovchok, D., et al. (2018b). In situ characterization of $\mathrm{Cu} / \mathrm{CeO}_{2}$ nanocatalysts for RWGSR: morphological effects of nanostructured ceria on the cataystic activity. J. Phys. Chem. C 122, 12934-12943. doi: 10.1021/acs.jpcc.8b03596

Lin, W., Stocker, K. M., and Schatz, G. C. (2017). Mechanisms of hydrogenassisted $\mathrm{CO}_{2}$ reduction on nickel. J. Am. Chem. Soc. 139, 4663-4666. doi: 10.1021/jacs.7b01538

Liu, B. W., Ju, Y. W., Abe, T., and Kawamoto, K. (2015). Dispersion and distribution of bimetallic oxides in SBA-15, and their enhanced activity for reverse water gas shift reaction. Irong. Chem. Front. 2, 741-748. doi: 10.1039/C5QI00062A

Liu, D. Y., Li, Y. Y., Kottwitz, M., Yan, B. H., Yao, S. Y., Gamalski, A., et al. (2018). Identifying dynamic structural changes of active sites in Pt-Ni bimetallic catalysts using multimodal approaches. ACS Catal. 5, 4120-4131. doi: $10.1021 /$ acscatal.8b00706

Liu, L., Das, S. L., Chen, T. J., Dewangan, N., Ashok, J., Xi, S. B., et al. (2020). Low temperature catalytic reverse water-gas shift reaction over perovskite catalysts in DBD plasma. Appl. Catal. B-Environ. 265:118573. doi: 10.1016/j.apcatb.2019.118573

Liu, L. N., Fan, F., Bai, M. M., Xue, F., Ma, X. R., Jiang, Z., et al. (2019). Mechanistic study of methanol synthesis from $\mathrm{CO}_{2}$ hydrogenation on $\mathrm{Rh}$-doped $\mathrm{Cu}(111)$ surfaces. Mol. Catal. 466, 26-36. doi: 10.1016/j.mcat.2019.01.009

Liu, X. Y., Wang, A. Q., Zhang, T., and Mou, C. Y. (2013). Catalysis by gold: new insights into the support effect. Nano Today 8, 403-416. doi: 10.1016/j.nantod.2013.07.005

Liu, Y., and Liu, D. Z. (1999). Study of bimetallic $\mathrm{Cu}-\mathrm{Ni} / \gamma-\mathrm{Al}_{2} \mathrm{O}_{3}$ catalysts for carbon dioxide hydrogenation. Int. J. Hydrogen. Energy 24, 351-354. doi: 10.1016/S0360-3199(98)00038-X

Liu, Y., Zhang, C. H., Wang, Y., Li, Y., Hao, X., Bai, L., et al. (2008). Effect of cofeeding carbon dioxide on fischer-tropsch synthesis over an iron-manganese catalyst in a spinning basket reactor. Fuel Process. Technol. 89, 234-241. doi: 10.1016/j.fuproc.2007.11.002

Lu, B. W., and Kawamoto, K. (2014). Preparation of mesoporous $\mathrm{CeO}_{2}$ and monodispersed $\mathrm{NiO}$ particles in $\mathrm{CeO}_{2}$, and enhanced selectivity of $\mathrm{NiO} / \mathrm{CeO}_{2}$ for reverse water gas shift reaction. Mater. Res. Bull. 53, 70-78. doi: 10.1016/j.materresbull.2014.01.043

Maiti, D., Daza, Y. A., Yung, M. M., Kuhn, J. N., and Bhethanabotla, V. R. (2016). Oxygen vacancy formation characteristics in the bulk and across different surface terminations of $\mathrm{La}_{(1-\mathrm{x})} \mathrm{Fe}_{(1-\mathrm{y})} \mathrm{Co}_{\mathrm{y}} \mathrm{O}_{(3-\delta)}$ perovskite oxides for $\mathrm{CO}_{2}$ conversion. J. Mater. Chem. A 4, 5137-5148. doi: 10.1039/C5TA10284G

Maitlis, P. M., Haynes Maitlis, A., Sunley, G. J., and Howard, M. J. (1996). Methanol carbonylation revisited: thirty years on. J. Chem. Soc. Dalton. 112, 2187-2196. doi: 10.1039/dt9960002187

Masui, T., Fujiwara, K., Machida, K., and Adachi, G. (1997). Characterization of Cerium(IV) oxide ultrafine particles prepared using reversed micelles. Chem. Mater. 9, 2197-2204. doi: $10.1021 / \mathrm{cm} 970359 \mathrm{v}$

Matsubu, J. C., Yang, V. N., and Christopher, P. (2015). Isolated metal active site concentration and stability control catalytic $\mathrm{CO}_{2}$ reduction selectivity. J. Am. Chem. Soc. 137, 3076-3084. doi: 10.1021/ja5128133

Matsubu, J. C., Zhang, Y., DeRita, L., Marinkovic, N. S., Chen, J. G., Graham, G. W., et al. (2017). Adsorbate-mediated strong metal-support interactions in oxide-supported Rh catalysts. Nat. Chem. 9, 120-127. doi: 10.1038/nchem.2607

Mikkelsen, M., Jørgensen, M., and Krebs, F. C. (2010). The teraton challenge. A review of fixation and transformation of carbon dioxide. Energy Environ. Sci. 3, 43-81. doi: 10.1039/B912904A

Millet, M. M., Algara-Siller, G., Wrabetz, S., Mazheika, A., Girgsdies, F., and Teschner, D. (2019). Ni single atom catalysts for $\mathrm{CO}_{2}$ activation. J. Chem. Soc. 141, 2451-2461. doi: 10.1021/jacs.8b11729

Min, B. K., Santra, A. K., and Goodman, D. W. (2003). Understanding silicasupported metal catalysts: $\mathrm{Pd} /$ silica as a case study. Catal. Today 85 , 113-124. doi: 10.1016/S0920-5861(03)00380-8
Mirzaei, A. A., R., Habibpour Faizi, M., and Kashi, E. (2006). Characterization of iron-cobalt oxide catalysts: effect of different supports and promoters upon the structure and morphology of precursors and catalysts. Appl. Catal. A-Gen. 301, 272-283. doi: 10.1016/j.apcata.2005.12.022

Morse, J. R., Juneau, M., Baldwin, J. W., Porosoff, M. D., and Willauer, H. D. (2020). Alkali promoted tungsten carbide as a selective catalysts for the reverse water gas shift reaction. J. $\mathrm{CO}_{2}$ Util. 35, 38-46. doi: 10.1016/j.jcou.2019.08.024

Mukherjee, D., Park, S. E., and Reddy, B. M. (2016). $\mathrm{CO}_{2}$ as a soft oxidant for oxidative dehydrogenation reaction: an eco-benign process for industry. J. $\mathrm{CO}_{2}$ Util. 16, 301-312. doi: 10.1016/j.jcou.2016.08.005

Naito, S., Aida, S. G., Kasahara, T., and Miyao, T. H. (2006). Infrared spectroscopic study on the reaction mechanism of $\mathrm{CO}$ hydrogenation over $\mathrm{Pd} / \mathrm{CeO}_{2}$. Res. Chem. Intermediat. 32, 279-290. doi: 10.1163/156856706777346444

Nakamura, I., Fujitani, T., Uchijima, T., and Nakamura, J. (1998). The synthesis of methanol and the reverse water-gas shift reaction over $\mathrm{Zn}$-deposited $\mathrm{Cu}(100)$ and $\mathrm{Cu}(110)$ surfaces: comparison with $\mathrm{Zn} / \mathrm{Cu}(111)$. Surf. Sci. 400, 387-400. doi: 10.1016/S0039-6028(97)00899-6

Neophytides, S. G., Zafeiratos, S., Papakonstantinou, G. D., Jaksic, J. M., Paloukis, F. E., and Jaksic, M. M. (2005). Extended brewer hypohyper-d-interionic bonding theory II. strong metal-support interaction grafting of composite electrocatalysts. Int. J. Hydrog. Energy 30, 393-410. doi: 10.1016/j.ijhydene.2004.07.005

Nielsen, D. U., Hu, X. M., Daasbjerg, K., and Skrydstrup, T. (2018). Chemically and electrochemically catalysed conversion of $\mathrm{CO}_{2}$ to $\mathrm{CO}$ with follow-up utilization to value-added chemicals. Nat. Catal. 1, 244-254. doi: 10.1038/s41929-018-0051-3

Nitarori, T., Ichiki, T., and Misono, M. (1988). Catalytic properties of perovskitetype mixed oxides $\left(\mathrm{ABO}_{3}\right)$ consisting of rare earth and $3 \mathrm{~d}$ transition metals. The roles of the A- and B-site ions. B Chem. Soc. Jpn 61, 621-626. doi: $10.1246 /$ bcsj.61.621

Obalová, L., Karásková K., Wach, A., Kustrowski, P., Mamulová-Kutláková K., Michalik, S., et al. (2013). Alkali metals as promoters in Co-Mn-Al mixed oxide for $\mathrm{N}_{2} \mathrm{O}$ decomposition. Appl. Catall. A-Gen. 462-463, 227-235. doi: 10.1016/j.apcata.2013.05.011

Okabe, K., Takahara, I., Inaba, M., Murata, K., and Yoshimura, Y. (2007). Effects of $\mathrm{Ru}$ precursors on activity of $\mathrm{Ru}-\mathrm{SiO}_{2}$ catalysts prepared by alkoxide method in Fisher-Tropsch synthesis. J. Jpn. Petrol. Inst. 50, 65-68. doi: 10.1627/jpi.50.65

Okemoto, A., Harada, M. R., Ishizaka, T., Hiyoshi, N., and Sato, K. (2020). Catalytic performance of Mo3/FAU zeolite catalysts modified by $\mathrm{Cu}$ for reverse water gas shift reaction. Appl. Catal. A-Gen. 592:117415. doi: $10.1016 /$ j.apcata.2020.117415

Pacultová, K., Draštíková V., Chromčáková Ž., Bílková T., Kutlákovác, K. M., Kotarba, A., et al. (2017). On the stability of alkail metal promoters in Co mixed oxides during direct NO catalytic decomposition. J. Mol. Catal. A Chem. 428, 33-40. doi: 10.1016/j.molcata.2016.11.038

Panarities, C., Zgheib, J., Ebrahim, S. A. H., Couillard, M., and Baranova, E. A. (2020). Electrochemical in-situ activation of Fe-oxide nanowires for the reverse water gas shift reaction. Appl. Catal. B-Environ. 269:118826. doi: 10.1016/j.apcatb.2020.118826

Panaritis, C., Edake, M., Couillard, M., Einakchi, R., and Baranova, E. A. (2018). Insight towards the role of ceria-based supports for reverse water gas shift reaction over RuFe nanopartilces. J. $\mathrm{CO}_{2}$ Util. 26, 350-358. doi: 10.1016/j.jcou.2018.05.024

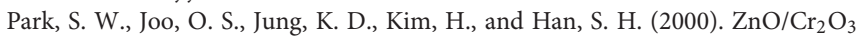
catalyst for reverse-water-gas shift reaction of CAMERE process. Korean J. Chem. Eng. 17, 719-722. doi: 10.1007/BF02699123

Park, S. W., Joo, O. S., Jung, K. D., Kim, H., and Han, S. H. (2001). Development of $\mathrm{ZnO} / \mathrm{Al}_{2} \mathrm{O}_{3}$ catalyst for reverse-water-gas-shift reaction of CAMERE (carbon dioxide hydrogenation to form methanol via a reverse-water-gas-shift reaction) process. Appl. Catal. A-Gen. 211, 81-90. doi: 10.1016/S0926-860X(00)00840-1

Pastor-Pérez, L., Shah, M., Saché L. E., and Reina, T. R. (2018). Improving $\mathrm{Fe} / \mathrm{Al}_{2} \mathrm{O}_{3}$ catalysts for the reverse water-gas shift reaction: on the effect of Cs as activity/selectivity promoter. Catalysts 8:608. doi: 10.3390/catal8120608

Peña, M. A., and Fierro, J. L. G. (2001). Chemical structures and performance of perovskite oxides. Chem. Rev. 101, 1981-2017. doi: 10.1021/cr980129f

Porosoff, M. D., and Chen, J. G. (2013). Trends in the catalytic reduction of $\mathrm{CO}_{2}$ by hydrogen over supported monometallic and bimetallic catalysts. J. Catal. 301, 30-37. doi: 10.1016/j.jcat.2013.01.022 
Porosoff, M. D., Yan, B. H., and Chen, J. G. (2016). Catalytic reduction of $\mathrm{CO}_{2}$ by $\mathrm{H}_{2}$ for synthesis of $\mathrm{CO}$, methanol and hydrocarbons: challenges and opportunities. Energ. Environ. Sci. 9: 62-73. doi: 10.1039/C5EE02657A

Porosoff, M. D., Yang, X. F., Boscoboinik, J. A., and Chen, J. G. (2014). Molybdenum carbide as alternative catalysts to precious metals for highly selective reduction of $\mathrm{CO}_{2}$ to CO. Angew. Chem. Int. Ed. 53, 6705-6709. doi: 10.1002/anie.201404109

Qian, C. X., Sun, W., Hung, D. L. H., Qiu, C. Y., Makaremi, M., Kumar, S. G. H., et al. (2019). Catalytic $\mathrm{CO}_{2}$ reduction by palladium-decorated silicon-hydride nanosheets. Nat. Catal. 2, 46-54. doi: 10.1038/s41929-018-0199-x

Radovic, M., Speakman, S. A., Allard, L. F., Payzant, E. A., Lara-Curzio, E., Kriven, W. M., et al. (2008). Thermal, mechanical and phase stability of $\mathrm{LaCoO}_{3}$ in reducing and oxidizing environments. J. Power Sour. 184, 77-83. doi: 10.1016/j.jpowsour.2008.05.063

Ranjabar, A., Irankhah, A., and Aghamiri, S. F. (2019). Catalytic activity of rare earth and alkali metal promoted $(\mathrm{Ce}, \mathrm{La}, \mathrm{Mg}, \mathrm{K}) \mathrm{Ni} / \mathrm{Al}_{2} \mathrm{O}_{3}$ nanocatalysts in reverse water gas shift reaction. Res. Chem. Intermediat. 45, 5125-5141. doi: 10.1007/s11164-019-03905-1

Rao, K. N., Reddy, B. M., Abhishek, B., Seo, Y. H., Jiang, N. Z., and Park, S. E. (2009). Effect of ceria on the structure and catalytic activity of $\mathrm{V}_{2} \mathrm{O}_{5} / \mathrm{TiO}_{2}$ $\mathrm{ZrO}_{2}$ for oxidehydrogenation of ethylbenzene to styrene utilizing $\mathrm{CO}_{2}$ as soft oxidant. Appl. Catal. B-Environ. 91, 649-656. doi: 10.1016/j.apcatb.2009.07.003

Reddy, B. M., Han, D. S., Jiang, N. Z., and Park, S. E. (2008). Dehydrogenation of ethylbenzene to styrene with carbon dioxide over $\mathrm{ZrO}_{2}$-based composite oxide catalysts. Catal. Surv. Asia 12, 56-69. doi: 10.1007/s10563-007-9039-8

Reddy, B. M., Katta, L., and Thrimurthulu, G. (2010). Novel nanocrystalline $\mathrm{Ce}_{1-\mathrm{x}} \mathrm{La}_{\mathrm{x}} \mathrm{O}_{2-\delta}(\mathrm{x}=0.2)$ solid solutions: structural characteristics and catalytic performance. Chem. Mater. 22, 467-475. doi: $10.1021 / \mathrm{cm} 903282 \mathrm{w}$

Riedel, T., Claeys, M., Schulz, H., Schaub, G., Nam, S. S., Jun, K. W., et al. (1999). Comparative study of fischer-tropsch synthesisi with $\mathrm{H}_{2} / \mathrm{CO}$ and $\mathrm{H}_{2} / \mathrm{CO}_{2}$ syngas using Fe- and Co-based catalysts. Appl. Catal. A-Gen. 186, 201-203. doi: 10.1016/S0926-860X(99)00173-8

Ringuedẽ A., and Fouletier, J. (2001). Oxygen reaction on strontium-doped lanthanum cobaltite dense electrodes at intermediate temperatures. Solid State Ionics 139, 167-177. doi: 10.1016/S0167-2738(01)00692-0

Ro, I., Sener, C., Stadelman, T. M., Ball, M. R., Venegas, J. M., Burt, S. P., et al. (2016). Measurement of intrinsic catalytic activity of Pt monometallic and Pt-MoOx interfacial sites over visible light enhanced $\mathrm{PtMoOx} / \mathrm{SiO}_{2}$ catalyst in reverse water gas shift reaction. J. Catal. 344, 784-794. doi: 10.1016/j.jcat.2016.08.011

Rogowski, J. (2019). TOF-SIMS study of morphology and chemical composition of wustite-based precursor and iron catalyst for ammonia synthesis. Appl. Sur. Sci. 469, 82-89. doi: 10.1016/j.apsusc.2018.10.271

Roiaz, M., Monachino, E., Dri, C., Greiner, M., Knop-Gericke, A., Schlögl, R., et al. (2016). Reverse water-gas shift or Sabatier methanation on $\mathrm{Ni}(110)$ ? Stable surface species at near ambient pressure. J. Am. Chem. Soc. 138, 4146-4154. doi: $10.1021 /$ jacs.5b13366

Ronda-Lloret, M., Rico-Francés, S., Sepúlveda-Escribano, A., and RamosFernandez, E. V. (2018). $\mathrm{CuOx} / \mathrm{CeO}_{2}$ catalyst derived from metal organic framework for reverse water-gas shift reaction. Appl. Catal. A-Gen. 562, 28-36. doi: 10.1016/j.apcata.2018.05.024

Royer, S., Duprez, D., and Kaliaguine, S. (2005). Role of bulk and grainboundary oxygen mobility in the catalytic oxidation activity of $\mathrm{LaCo}_{1-\mathrm{x}} \mathrm{Fe}_{\mathrm{x}} \mathrm{O}_{3}$. J. Catal. 234, 364-375. doi: 10.1016/j.jcat.2004.11.041

Sache, E. L., Pastor-Pérez, L., Haycock, B. J., Villora-Pic,ó J. J., SepúlvedaEscribano, A., and Ramirez Reina, T. (2020). Switchable catalysts for chemical $\mathrm{CO}_{2}$ recycling: A step forward in the methanation and reverse water-gas shift reactions. ACS Sustain. Chem. Eng. 11, 4614-4622. doi: 10.1021/acssuschemeng.0c00551

Saeidi, S., Najari, S., Fazlollahi, F., Nikoo, M. F., Sefidkon, F., Klemes, J. J., et al. (2017). Mechanisms and kinetics of $\mathrm{CO}_{2}$ hydrogenation to value-added products: A detailed review on current status and future trends. Renew. Sust. Energ. Rev. 80, 1292-1311. doi: 10.1016/j.rser.2017.05.204

Sahebdelfar, S., and Takht Ravanchi, M. (2015). Carbon dioxide utilization for methane production: A thermodynamic analysis, J. Petrol. Sci. Eng. 134 14-22. doi: 10.1016/j.petrol.2015.07.015

Schmale, K., Daniels, M., Buchheit, A., Grünebaum, M., Haase, L., Koops, S., et al. (2013). Influence of zinc oxide on the conductivity of ceria. J. Electrochem. Soc. 160, 1081-1087. doi: 10.1149/2.1193 09jes

Shimoda, N., Kimura, Y., Kobayashi, Y., Kubota, J., and Satokawa, S. (2017). Ammonia synthesis over yttrium-doped barium zirconate and cerate-based perovskite-type oxide supported ruthenium catalysts. Int. J. Hydrog. Energ. 42, 29745-29755. doi: 10.1016/j.ijhydene.2017.10.108

Silva-Calpa, L. D. R., Zonetti, P. C., Rodrigues, C. P., Alves, O. C., Appel, L. G., and de Avillez, R. R. (2016). The $\mathrm{Zn}_{\mathrm{x}} \mathrm{Zr}_{1-\mathrm{x}} \mathrm{O}_{2-\mathrm{y}}$ solid solution on $\mathrm{m}-\mathrm{ZrO}_{2}$ : creating $\mathrm{O}$ vacancies and improving the $\mathrm{m}-\mathrm{ZrO}_{2}$ redox properties. J. Mol. Catal. A-Chem. 425, 166-173. doi: 10.1016/j.molcata.2016.10.008

Su, X., Yang, X. F., Huang, Y. Q., Liu, B., and Zhang, T. (2019). Single-atom catalysis toward efficient $\mathrm{CO}_{2}$ conversion to $\mathrm{CO}$ and formate products. Acc. Chem. Res. 52, 656-664. doi: 10.1021/acs.accounts.8b00478

Su, X., Yang, X. L., Zhao, B., and Huang, Y. Q. (2017). Designing of highly selective and high-temperature endurable RWGSR heterogeneous catalysts: recent advances and the future directions. J. Energy Chem. 26, 854-867. doi: 10.1016/j.jechem.2017.07.006

Sun, C. W., Li, H., and Chen, L. Q. (2012). Nanostructured ceria-based materials: synthesis, properties, and applications. Energy Environ. Sci. 5, 8475-8505. doi: $10.1039 / \mathrm{c} 2 \mathrm{ee} 22310 \mathrm{~d}$

Sun, F. M., Yan, C. F., Wang, Z. D., and Guo, C. Q. (2015). Ni/Ce-Zr-O catalyst for high $\mathrm{CO}_{2}$ conversion during reverse water gas shift reaction (RWGSR). Int. J. Hydrog. Energ. 40, 15985-15993. doi: 10.1016/j.ijhydene.2015.10.004

Sun, Q. D., Ye, J. Y., and Liu, C. J. (2014). $\mathrm{In}_{2} \mathrm{O}_{3}$ as a promising catalyst for $\mathrm{CO}_{2}$ utilization: a case study with reverse water gas shift over $\operatorname{In}_{2} \mathrm{O}_{3}$. Greenhouse Gases 4, 140-144. doi: 10.1002/ghg.1401

Tang, Q. L., Hong, Q. J., and Liu, Z. P. (2009). $\mathrm{CO}_{2}$ fixation into methanol at $\mathrm{Cu} / \mathrm{ZrO}_{2}$ interface from first principles kinetic Monte Carlo. J. Catal. 263, 114-122. doi: 10.1016/j.jcat.2009.01.017

Ten Elshof, J. E., Bouwmeester, H. J. M., and Verweij, H. (1996). Oxygen transport through $\mathrm{La}_{1-X} \mathrm{Sr}_{\mathrm{X}} \mathrm{FeO}_{3-\delta}$ membranes II. Permeation in air/CO, $\mathrm{CO} 2$ gradients. Solid State Ionics 89, 81-92. doi: 10.1016/0167-2738(96)00255-X

Tibiletti, D., Goguet, A., Meunier, F. C., Breen, J. P., and Burch, R. (2004). On the importance of steady-state isotopic techniques for the investigation of the mechanism of the reverse water-gas-shift reaction. Chem. Commun. 14, 1636-1637. doi: 10.1039/b403438d

Utsis, N., Landau, M. V., Erenburg, A., Nehemya, R. V., and Hersowitz, M. (2018). Performance of reverse water gas shift on co-precipitated and carbontemplated BaFe-hexaaluminate effect of iron loading, texture, and promotion with Postassium. ChemCatChem 10, 3795-3805. doi: 10.1002/cctc.201800709

Wang, C. C., and Nakamura, J. (2010). Structure sensitivity for forward and reverse water-gas shift reactions on copper structure surfaces: a DFT study. J. Phys. Chem. Lett. 1, 3053-3057. doi: 10.1021/jz101150w

Wang, F., He, S., Chen, H., Wang, B., Zheng, L. R., Wei, M., et al. (2016b). Active site dependent reaction mechanism over $\mathrm{Ru} / \mathrm{CeO}_{2}$ catalyst toward $\mathrm{CO}_{2}$ methanation. J. Am. Chem. Soc. 138, 6298-6305. doi: 10.1021/jacs.6b02762

Wang, G. C., Jiang, L., Pang, X. Y., Cai, Z. S., Pan, Y. M., Zhao, X. Z., et al. (2003). A theoretical study of surface-structural sensitivity of the reverse water-gas shift reaction over $\mathrm{Cu}(h k l)$ surfaces. Surf. Sci. 543, 118-130. doi: 10.1016/S0039-6028(03)00876-8

Wang, J. Y., Liu, C. Y., Senfile, T. P., Zhu, J., Zhang, G. H., Guo, X. W., et al. (2020). Variation in $\operatorname{In}_{2} \mathrm{O}_{3}$ crystal phase alters catalytic performance toward the reverse water gas shift reaction. ACS Catal. 10, 3264-3273. doi: $10.1021 /$ acscatal.9b04239

Wang, L., Liu, H., Liu, Y., Chen, Y., and Yang, S. Q. (2013a). Effect of precipitants on $\mathrm{Ni}-\mathrm{CeO}_{2}$ catalysts prepared by a co-precipitation method for the reverse water-gas shift reaction. J. Rare Earths 31, 969-974. doi: 10.1016/S1002-0721(13)60014-9

Wang, L. C., Khazaneh, M. T., Widmann, D., and Behm, R. J. (2013b). TAP reactor studies of the oxidizing capability of $\mathrm{CO}_{2}$ on a $\mathrm{Au} / \mathrm{CeO}_{2}$ catalyst - A first step toward identifying a redox mechanism in the reverse water-gas shift reaction. J. Catal. 302, 20-30. doi: 10.1016/j.jcat.2013.02.021

Wang, L. H., and Liu, H. (2018). Mesoporous $\mathrm{Co}-\mathrm{CeO}_{2}$ catalyst prepared by colloidal solution combustion method for reverse water-gas shift reaction. Catal. Today 316, 155-161. doi: 10.1016/j.cattod.2018.04.015

Wang, L. H., Liu, H., Chen, Y., Zhang, R. K., and Yang, S. Q. (2013c). K-promoted $\mathrm{Co}-\mathrm{CeO}_{2}$ catalyst for reverse water-gas shift reaction. Chem. Lett. 42, 682-683. doi: 10.1246/cl.130137 
Wang, L. H., Liu, H., Liu, Y., Chen, Y., and Yang, S. Q. (2013d). Influence of preparation method on performance of $\mathrm{Ni}-\mathrm{CeO}_{2}$ catalysts for reverse water-gas shift reaction. J. Rare Earths 31, 559-564. doi: 10.1016/S1002-0721(12)60320-2

Wang, W., Wang, S. P., Ma, X. B., and Gong, J. L. (2011). Recent advances in catalytic hydrogenation of carbon dioxide. Chem. Soc. Rev. 40, 3703-3727. doi: $10.1039 /$ clcs15008a

Wang, W., Zhang, Y., Wang, Z. Y., Yan, J. M., Ge, Q. F., and Liu, C. J. (2016c). Reverse water gas shift over $\mathrm{In}_{2} \mathrm{O}_{3}-\mathrm{CeO}_{2}$ catalysts. Catal. Today 259, 402-408. doi: 10.1016/j.cattod.2015.04.032

Wang, X., Hong, Y. C., Shi, H., and Szanyi, J. (2016a). Kinetic modeling and transient DRIFTS-MS studies of $\mathrm{CO}_{2}$ methanation over $\mathrm{Ru} / \mathrm{Al}_{2} \mathrm{O}_{3}$ catalysts. J. Catal. 343, 185-195. doi: 10.1016/j.jcat.2016.02.001

Wang, X., Shi, H., Kwak, J. H., and Szanyi, J. (2015). Mechanism of $\mathrm{CO}_{2}$ hydrogenation on $\mathrm{Pd} / \mathrm{Al}_{2} \mathrm{O}_{3}$ catalysts: Kinetics and transient DRIFTS-MS studies. ACS Catal. 5, 6337-6349. doi: 10.1021/acscatal.5b01464

Wang, X., Shi, H., and Szanyi, J. (2017). Controlling selectivities in $\mathrm{CO}_{2}$ reduction through mechanistic understanding. Nat. Commun. 8, 513-518. doi: 10.1038/s41467-017-00558-9

Wang, Y. X., and Wang, G. C. (2019). A systematic theoretical study of water gas shift reaction on $\mathrm{Cu}(111)$ and $\mathrm{Cu}(110)$ : potassium effect. ACS Catal. 9, 2261-2274. doi: 10.1021/acscatal.8b04427

Weatherbee, G. D., and Bartholomew, C. H. (1984). Hydrogenation of $\mathrm{CO}_{2}$ on group-VIII metals.4. Specific activities and selectivities of silica-supported Co, Fe, and Ru. J. Catal. 87, 352-362. doi: 10.1016/0021-9517(84)90196-9

Wenzel, M., Dharanipragada, V. R. A., Galvita, V. V., Poelman, H., Marin, G. B., Rihko-Struckmann, L., et al. (2017). CO product from $\mathrm{CO}_{2}$ via reverse watergas shift reaction performed in a chemical looping mode: Kinetics on modified iron oxide. J. $\mathrm{CO}_{2}$ Util. 17, 60-68. doi: 10.1016/j.jcou.2016.10.015

Wenzel, M., Rihko-struckmann, L., and Sundmacher, K. (2018). Continuous production of CO from $\mathrm{CO}_{2}$ by RWGSR chemical looping in fixed and fluidized bed reactors. Chem. Eng. J. 336, 278-296. doi: 10.1016/j.cej.2017.12.031

Wolf, A., Jess, A., and Kern, C. (2016). Syngas production via reverse water-gas shift reaction over a Ni/ $\mathrm{Al}_{2} \mathrm{O}_{3}$ catalyst: catalyst stability, reaction kinetics, and modelling. Chem. Eng. Technol. 39, 1040-1048. doi: 10.1002/ceat.201500548

Wu, H. C., Chang, Y. C., Wu, J. H., Lin, J. H., Lin, I. K., and Chen, C. S. (2015). Methanation of $\mathrm{CO}_{2}$ and reverse water gas shift reactions on $\mathrm{Ni} / \mathrm{SiO}_{2}$ catalysts: the influence of particle size on selectivity and reaction pathway. Catal. Sci. Technol. 5, 4154-4163. doi: 10.1039/C5CY00667H

Wu, X.-F., Neumann, H., and Beller, M. (2011). Palladium-catalyzed carbonylative coupling reactions between Ar-X and carbon nucleophiles. Chem. Soc. Rev. 40, 4986-5009. doi: 10.1039/clcs15109f

$\mathrm{Xu}, \mathrm{H} . \mathrm{C}$., and Ge, L. (2016). Progress on the catalytic hydrogenation of $\mathrm{CO}_{2}$ via reverse water gas shift reaction. Ind. Eng. Pro. 35, 3180-3189. doi: 10.16085/j.issn.1000-6613.2016.10.023

Yamazoe, N., Furukawa, S., Teraoka, Y., and Seiyama, T. (1982). The effect of oxygen sorption on the crystal structure of $\mathrm{La}_{1-X} \mathrm{Sr}_{\mathrm{X}} \mathrm{CoO}_{3-\delta}$. Chem. Lett. 10, 2019-2022. doi: 10.1246/cl.1982.2019

Yamazoe, N., Teraoka, Y., and Seiyama, T. (1981). TPD and XPS study on thermal behavior of absorbed oxygen in $\mathrm{La}_{1-\mathrm{X}} \mathrm{Sr}_{\mathrm{X}} \mathrm{CoO}_{3}$. Chem. Lett. 11, 1767-1770. doi: 10.1246/cl.1981.1767

Yang, Q., and Lin, J. Y. S. (2006). Fixed-bed performance for production of oxygen-enriched carbon dioxide stream by perovskite-type ceramic sorbent. Separation and purification technology. Sep. Purif. Technol. 49, 27-35. doi: 10.1016/j.seppur.2005.08.004

Yang, X. L., Su, X., Chen, X. D., Duan, H. M., Liang, B. L., Liu, Q. G., et al. (2017). Promotion effects of potassium on the activity and selectivity of Pt/zeolite catalysts for reverse water gas shift reaction. Appl. Catal. B-Environ. 216, 95-105. doi: 10.1016/j.apcatb.2017.05.067

Yao, X. J., Tang, C. J., Ji, Z. Y., Dai, Y., Cao, Y., Gao, F., et al. (2013). Investigation of the physicochemical properties and catalytic activities of $\mathrm{Ce}_{0.67} \mathrm{M}_{0.33} \mathrm{O}_{2}(\mathrm{M}$ $=\mathrm{Zr}^{4+}, \mathrm{Ti}^{4+}, \mathrm{Sn}^{4+}$ ) solid solutions for NO removal by CO. Catal. Sci. Technol. 3, 688-698. doi: 10.1039/C2CY20610B

Ye, J. Y., Liu, C. J., and Ge, Q. F. (2012). DFT study of $\mathrm{CO}_{2}$ adsorption and hydrogenation on the $\mathrm{In}_{2} \mathrm{O}_{3}$ surface. J. Phys. Chem. C 116, 7817-7825. doi: $10.1021 /$ jp3004773

Ye, J. Y., Liu, C. J., Mei, D. H., and Ge, Q. F. (2013). Active oxygen vacancy site for methanol synthesis from RWGSR on $\operatorname{In}_{2} \mathrm{O}_{3}$ (110): a DFT study. ACS Catal. 3, 1293-1306. doi: $10.1021 / \operatorname{cs} 400132$ a
Yeung, C. M. Y., Yu, K. M. K., Fu, Q. J., Thompsett, D., Petch, M. I., and Tsang, S. C. (2005). Engineering Pt in ceria for a maximum metal-support interaction in catalysis. J. Am. Chem. Soc. 127, 18010-18011. doi: 10.1021/ja056102c

Zhang, Q., and Guo, L. (2018). Mechanism of the reverse water-gas shift reaction catalyzed by $\mathrm{Cu}_{12} \mathrm{TM}$ bimetallic nanocluster: a density functional theory study. J. Clust. Sci. 29, 867-877. doi: 10.1007/s10876-018-1346-x

Zhang, Q., Guo, L., and Hao, Z. J. (2018). Computational investigation of $\mathrm{M}_{1} / \mathrm{W}_{6} \mathrm{~S}_{8}(\mathrm{M}=\mathrm{Fe}, \mathrm{Ru}$, and $\mathrm{Os})$ single-atom catalysts for $\mathrm{CO}_{2}$ hydrogenation. Catal. Surv. Asia 22, 195-207. doi: 10.1007/s10563-018-9252-7

Zhang, Q., Pastor-Pérez, L., Jin, W., Gu, S., and Reina, T. R. (2019b). Understanding the promoter effect of $\mathrm{Cu}$ and $\mathrm{Cs}$ over highly effective $\beta-\mathrm{Mo}_{2} \mathrm{C}$ catalysts for the reverse water-gas shift reaction. Appl. Catal. B-Environ. 244, 889-898. doi: 10.1016/j.apcatb.2018.12.023

Zhang, X., Zhu, X. B., Lin, L. L., Yan, S. Y., Zhang, M. T., Liu, X., et al. (2016). Highly dispersed copper over $\beta-\mathrm{Mo}_{2} \mathrm{C}$ as an efficient and stable catalyst for the reverse water gas shift (RWGSR) reaction. ACS Catal. 7, 912-918. doi: 10.1021/acscatal.6b02991

Zhang, Y., Liang, L., Chen, Z. Y., Wen, J. J., Zhong, W., Zou, S. B., et al. (2020), Highly efficient $\mathrm{Cu} / \mathrm{CeO}_{2}$-hollow nanospheres catalyst for the reverse water-gas shift reaction: Investigation on the role of oxygen vacancies through in situ UV-Raman and DRIFTS. Appl. Sur. Sci. 516:146035. doi: 10.1016/j.apsusc.2020.146035

Zhang, Z. M., Xun, H., Wang, Y., Hu, S., Xiang, J., Li, C. C., et al. (2019a). Regulation the reaction intermediates in methanation reactions vis modification of nickel catalysts with strong base. Fuel 237, 566-579. doi: 10.1016/j.fuel.2018.10.052

Zheng, X. L., Guo, L., Li, W. L., Cao, Z. R., Liu, N. Y., Zhang, Q., et al. (2017). Insight into the mechanism of reverse water-gas shift reaction and ethanol formation catalyzed by $\mathrm{Mo}_{6} \mathrm{~S}_{8}-\mathrm{TM}$ clusters. Mol. Catal. 439, 155-162. doi: 10.1016/j.mcat.2017.06.030

Zheng, Z. Z., Xu, H. T., Xu, Z. L., and Ge, J. P. (2018). A monodispersed spherical Zr-based metal-organic framework catalyst, Pt/Au@Pd@UIO-66, comprising an Au@Pd core-shell encapsulated in a UIO-66 center and its highly selective RWGSR to produce CO. Small 14:1702812. doi: 10.1002/smll.201702812

Zhou, G., Dai, B., Xie, H. M., Zhang, G. Z., Xiong, K., and Zheng, X. X. J. (2017). CeCu composite catalyst for CO synthesis by reverse watergas shift reaction: effect of $\mathrm{Ce} / \mathrm{Cu}$ mole ratio. $\mathrm{CO}_{2}$ Util. 21, 292-301. doi: 10.1016/j.jcou.2017.07.004

Zhou, G. L., Xie, F. Q., Deng, L. D., Zhang, G. Z., and Xie, H. M. (2020). Supported mesoporous $\mathrm{Cu} / \mathrm{CeO}_{2}-\delta$ catalyst for $\mathrm{CO}_{2}$ reverse watergas shift reaction to syngas. Int. J. Hydrog. Energy 45, 11380-11393. doi: 10.1016/j.ijhydene.2020.02.058

Zhou, K., and Li, Y. D. (2012). Catalysis based on nanocrystals with welldefined facets. Angew. Chem. Int. Ed. 51, 602-613. doi: 10.1002/anie.2011 02619

Zhou, P., Ma, Y. C., Lan, G. J., Tang, H. D., Han, W. F., Liu, H. Z., et al. (2019). A highly stable and active mesoporous rethenium catalyst for ammonia synthesis prepared by a $\mathrm{RhCl}_{3} / \mathrm{SiO}_{2}$-templated approach. Chinese J. Catal. 40, 114-123. doi: 10.1016/S1872-2067(18)63192-4

Zhuang, S. J., Han, N., Wang, T. T., Meng, X. X., Meng, B., Li, Y., et al. (2019). Enhanced CO selectivity for reverse water-gas shift reaction using $\mathrm{Ti}_{4} \mathrm{O}_{7}$-doped $\mathrm{SrCe}_{0.9} \mathrm{Y}_{0.1} \mathrm{O}_{3-\delta}$ hollow fibre membrane reaction. Canad. J. Chem. Eng. 97, 1619-1626. doi: 10.1002/cjce.23384

Zonetti, P. C., Letichevsky, S., Gaspar, A. B., Sousa-Aguiar, E. F., and Appel, L. G. (2014). The $\mathrm{NixCe}_{0.75} \mathrm{Zr}_{0.25-\mathrm{x}} \mathrm{O}_{2}$ solid solution and the RWGSR. Appl. Catal. A-Gen. 475, 48-54. doi: 10.1016/j.apcata.2014.01.004

Conflict of Interest: The authors declare that the research was conducted in the absence of any commercial or financial relationships that could be construed as a potential conflict of interest.

Copyright (C) 2020 Chen, Chen, Song, Ji, Wang, Wang and Cui. This is an open-access article distributed under the terms of the Creative Commons Attribution License (CC $B Y)$. The use, distribution or reproduction in other forums is permitted, provided the original author(s) and the copyright owner(s) are credited and that the original publication in this journal is cited, in accordance with accepted academic practice. No use, distribution or reproduction is permitted which does not comply with these terms. 